Bull. Fac .Agric., Cairo Univ. 64:228-243 (2013).

\title{
THE ECONOMIC EFFICIENCY OF SUGAR CANE CROP IN EGYPT (A CASE STUDY OF MINIA GOVERNORATE)
}

(Received:26.6.2013)

\author{
By \\ Y. H. A. Ali \\ The High Institute for Industrial Facilities, Sohag, Egypt
}

\begin{abstract}
Increasing the agricultural production by increasing the efficiency of using the available economic sources will lead to the increase of the revenue .Consequently this will increase the agricultural income in particular and the national income in general. These are the main goals for the agricultural economic policy. As the increases of the efficiency and economic produce of the available sources will lead to avoid the economic waste in using these sources from one side and directing these sources to the alternative agricultural uses which will give a great revenue from the other side. So, the cost of production will decrease, which will increase the ability of the agricultural produce to compete in the foreign markets. This research aimed in general to study the productivity and economic efficiency of the sources used in producing the sugar cane crop.

The annual average of the cultivated area of sugar cane in Egypt amounted to 316.07 thousand feddans during the period 1995 - 2012. The average produce for the feddan is 49.26 tons and the total, produce is 15778.16 tons where the price is 163.86 L.E. And, the average annual costs in total, the total revenue, the yield per feddan, profit of the pound spent in the season, the percentage of the total return to the total costs and the profit of the ton of sugar cane amounted to $4756.95-7739.24-2982,29-0.60-$ $1.60-60.64$ pounds, respectively. The average of the cultivated area of sugar cane in Minia was 33.98 thousand feddans during the period 1995 - 2011. The annual average of feddan productivity, the total produce of sugar cane amounted to 48.36 tons and 1651.95 thousand tons, respectively. The total annual costs, the total return, feddan return ,the profit of the pound spent in the season, the percentage of the total return to the total costs, the profit of the ton produced from sugar cane amounted to $4447.78-$ $7371.26-2923.48-0.61-60.59$, respectively.

On studying the economic efficiency of sugar cane crop in the sample studied in El-Minia, We divided this sample into three categories. We also discussed the problems which face the production of sugar cane crop in the sample studied in El-Minia. We also studied the estimate statistics for the produce, and costs.

In the light of the previous points, the study recommends the following points:

1-Trying to increase the productivity of feddan from sugar cane by using the modern technology in all production stages and implementing the recommendations of the devices of agricultural guidance and the national campaigns to promote the sugar cane crop.

2-Encouraging the research centres to breed new varieties of sugar cane which have high yield and can bear the lack of water and can be planted in the old and new lands.

3-Teaching farmers using the different factors such as seeds, fertilizers, automatic work and public costs so that they can achieve economic efficiency because rationalizing the use of these factors will increase the net of agricultural income.

4-There are some problems such as the high cost of fertilizers, high wages of human labour, the difficulty of getting loans from the agricultural credit device, the high prices of machines, the low level of irrigation water, the low price for selling the crop. So this study recommends the necessity of cooperation between the authorities responsible, especially the Ministery of Agriculture, the Ministery of Water Resources, the agricultural guidance device, the development banks, the councils for sugar crops and the companies of sugar cane because these authorities have an important role in providing farmers with all their needs for production and also providing them with loans and supplying them with irrigation projects to these lands to reduce the irrigation costs.
\end{abstract}

Key words: economic efficiency, minia governorate, sugar cane. 


\title{
الكفاءة الاقتصادية لمحصول قصب السكر في مصر

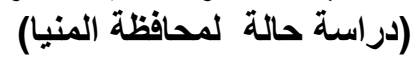 \\ ياسر حامدي عبد اللاه علي \\ المعهد العالي لادارة المنشأت الصناعية بسوهاج - مصر
}

\begin{abstract}
ملخص

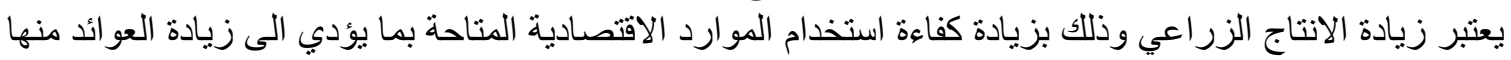

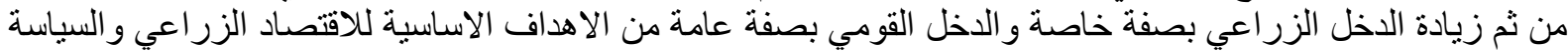

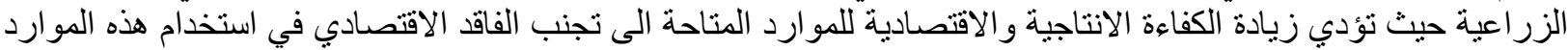

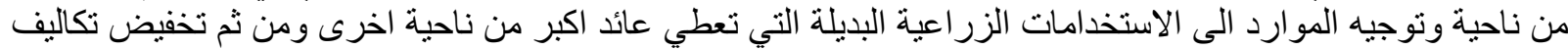

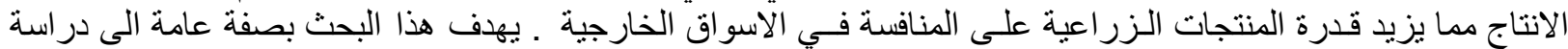

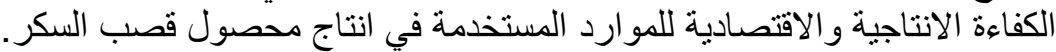

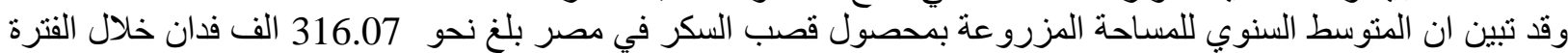

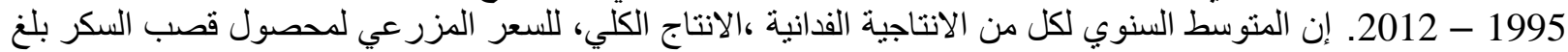

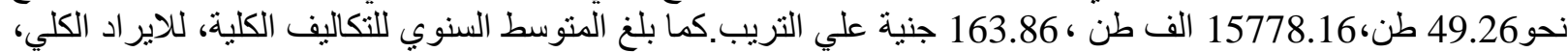

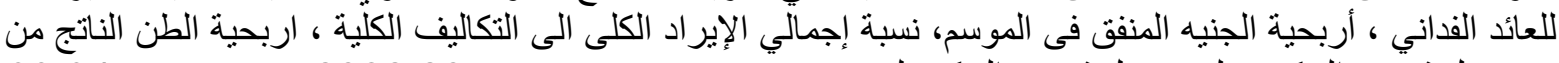
محصول قصب السكر ل لمحصول قصب السكر بلغ نحو 4756.95 ،

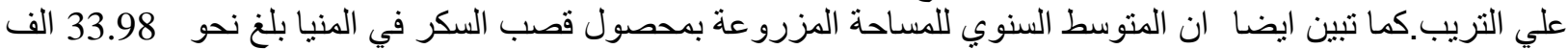

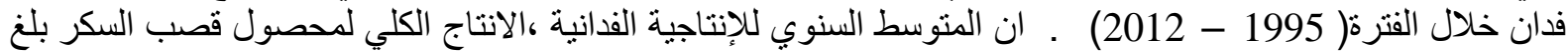

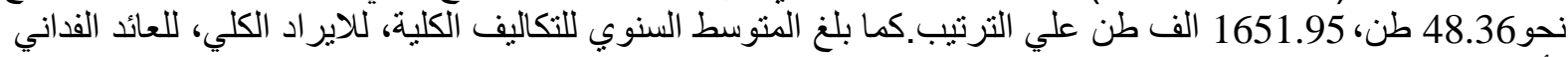

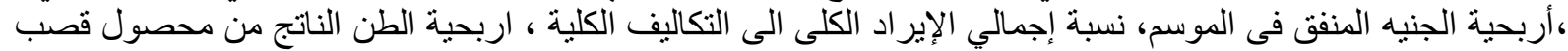

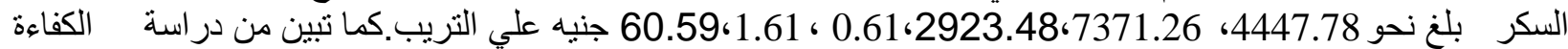

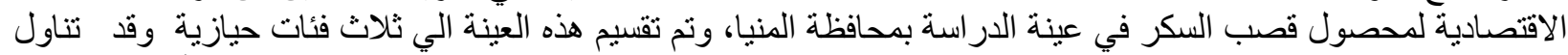

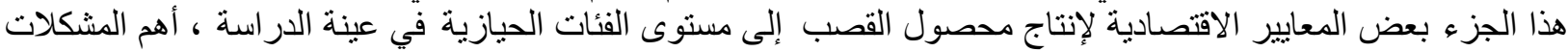

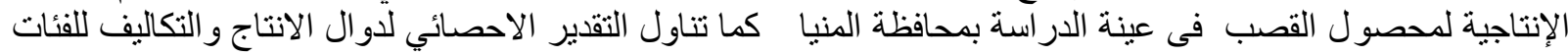
الحيازية الثالثة.

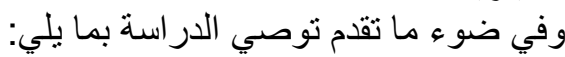

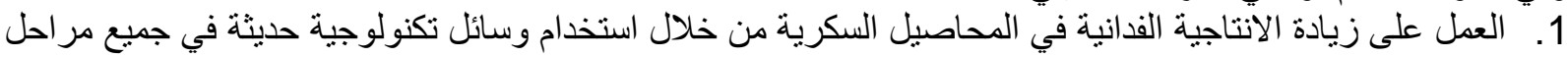

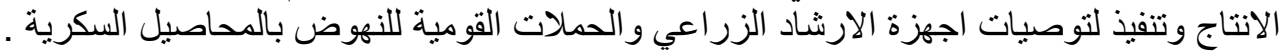

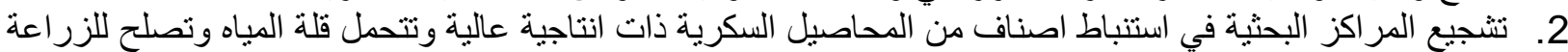

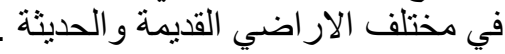

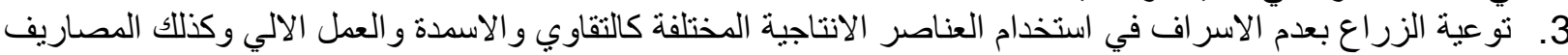

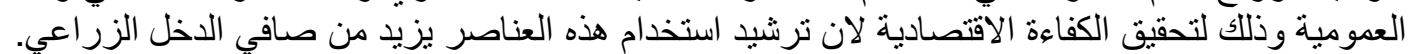

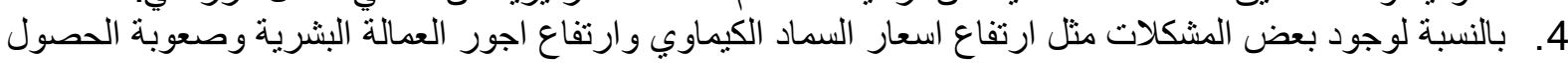

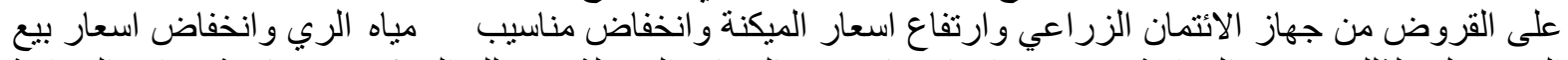

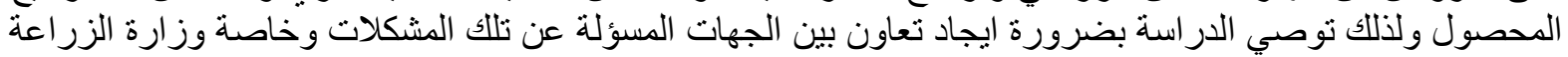

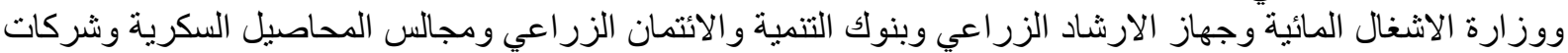

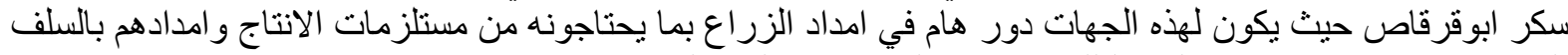

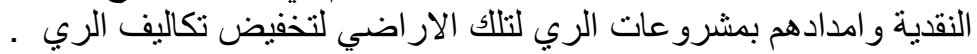

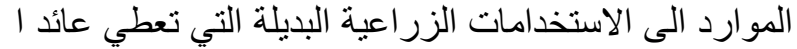

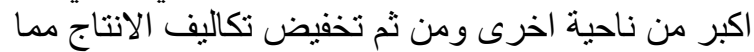

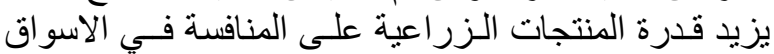

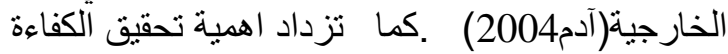

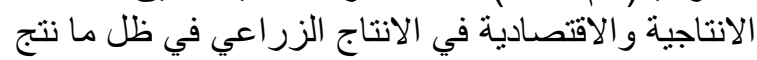

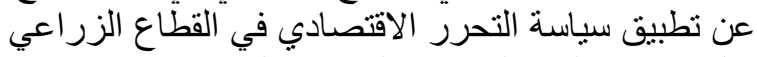

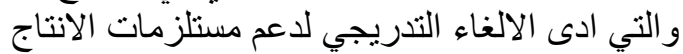
الزراعي الى ارتفاع اسعارها ، وكذللك ادى تحرير العلاقة الأنت

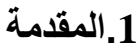

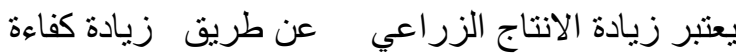

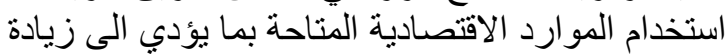

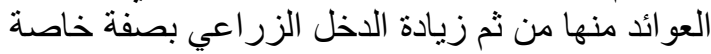

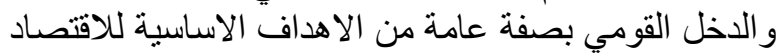

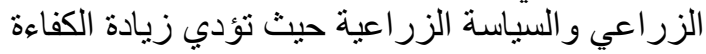

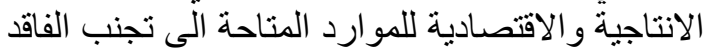
الاقتصادي في استخدام هذه الموارد من ناحية وتوجيه 


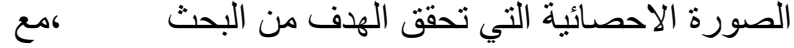

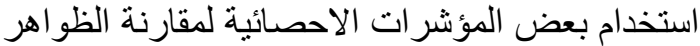

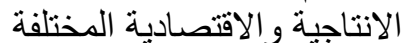

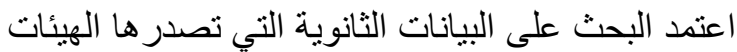

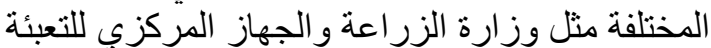

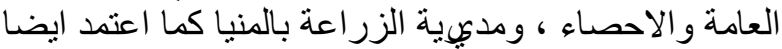

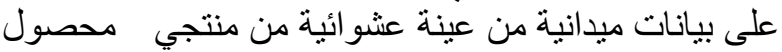
قصب السكر في محافظة المنيا من خلال استمارة الاستبيان

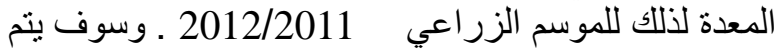

در اسة محصول قصب السكر علي مستوي الجمهورية ومحافظة المنيا كما بلي: مدولي:

\section{ولا: محصول قصب السكرفي مصر}

تطور المساحة المزروعة فمدان

تبين من الجدول رقم ( 1) ان المتوسط السنوي للمساحة المزروعة بمحصول قصب السكر بلغ نحو 316.07 الف الف الفئول فدان خلال الفترة( 1995 - 2012) بحد ادني بلغ

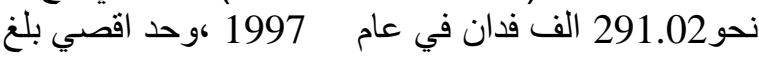

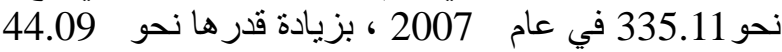

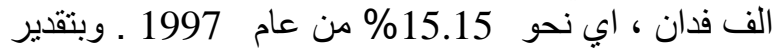

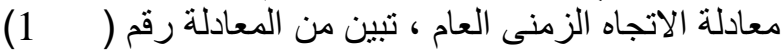

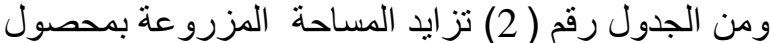
قصب السكر بمقدار معنوى إحصائيا بلغ نحو 1.54 الجئ 1.5

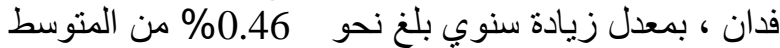
العام خلال فترة الدر استة ، وقد بلغ بلغ معامل التحديد نحو 0.75 مما بعني ان نحو 75\% من التغير ات الحادثة في المساحة

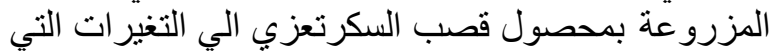
يعكسها عنصر الزمن. بمهن. تطور الانتاجية الفدانية

تبين من الجدول رقم ( 1) ان المتوسط السنوي للانتاجية الفدانية لمحصول قصب السكر بلغ نحو 49.26 طن خلال القترة (1995 - 2012) بحد ادني بلغ نحو 46.02 طن في في في في عام 1995 ،وحد اقصي بلغ نحو 1995 بـ 50.95 طن في عام 2006 ، بزيادة قدر ها نحو 4.93 طن ، اي نحو 10.71 10. من عام 1995 ـ وبتقدير معادلة الاتجاه الزمنى العادي العام ، تبين من المعادلة رقم (2) ومن الجدول رقم ( 2) تزيز ايد الانتاجية الفدانية لمحصول قصب السكر بمقدار معنوى إحصائيا بلغ نحو 0.14 طن ، بمعدل زيادة سنوي بلغ نحو

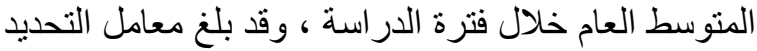

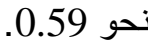

$$
\text { تطور الانتاج الكلي }
$$

تبين من الجدول رقم ( 1) الان المئ المتوسط السنوي للانتاج

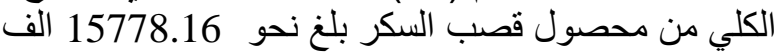

طن خلال الفترة( 1995 - 2012) بحد ادني بلغ نحو

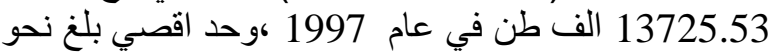

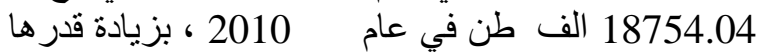

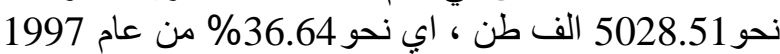

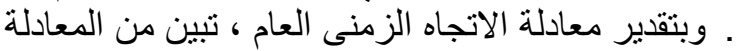

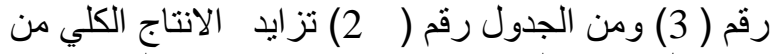

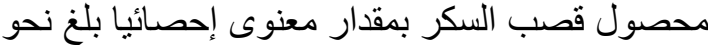

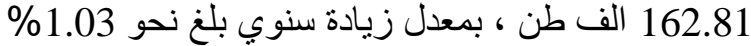

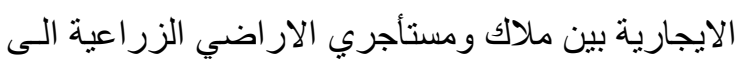

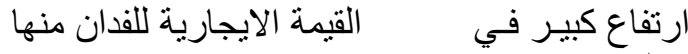

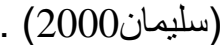

وتعبر الكفاءه بمفهومها العام عن العلاقة بين المدخلات

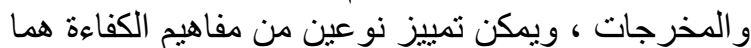

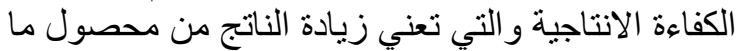

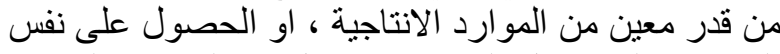

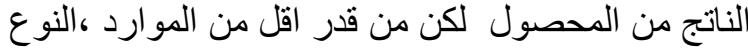

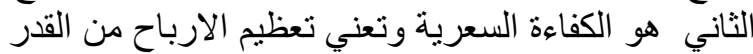

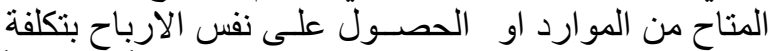

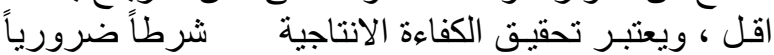

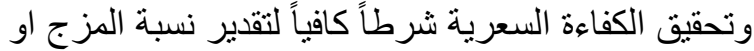
الخلط للموارد الانتاجية خلال المرحلة الاقتصادية العادية للانتاج

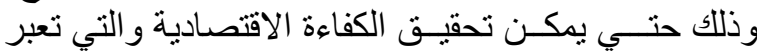

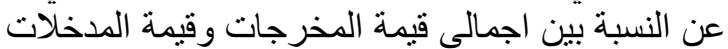
او العكس ( هدهد ، المو افى النى 2003).

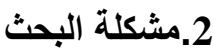

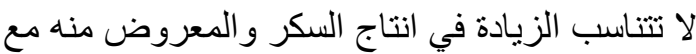

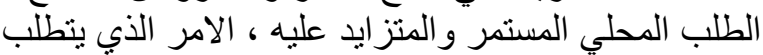

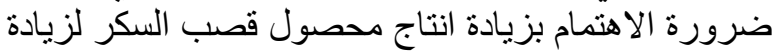

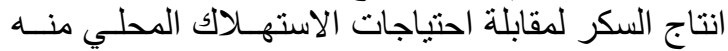

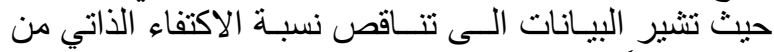

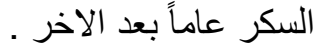

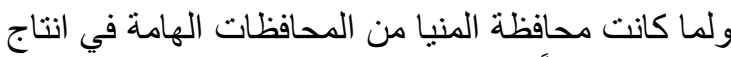

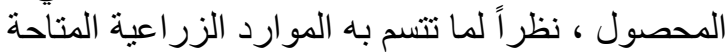

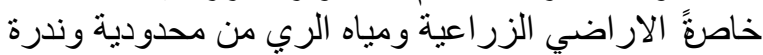

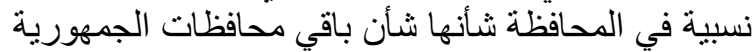

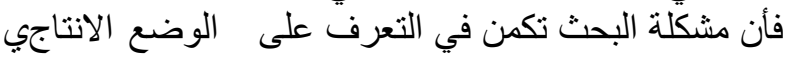

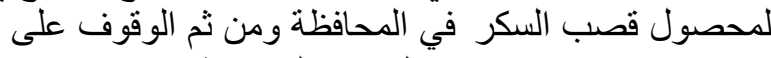

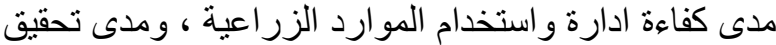

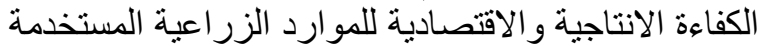

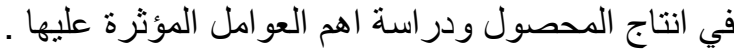

\section{3.الهوف من البحث}

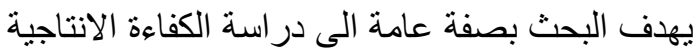

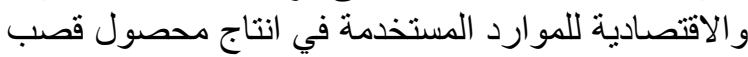

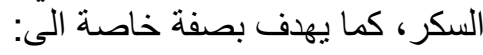

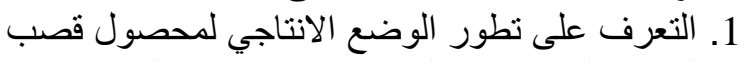
السكر على مستوى الجمهورية ومحافظة المنيا .

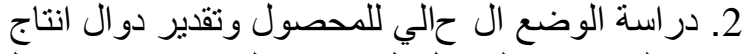

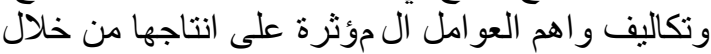
عينة الدر اسة بمحافظة المنيا .

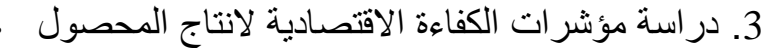

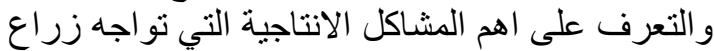
قصب السكر بالمحافظة الهم المنة الطريقة البحثية ومصادر البيانات باتئة

تم استخدام الطريق ة الوصفية ودية في البحثث مع استخدام

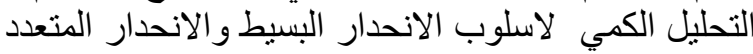
و المرحلي لقياس دوال الانتاج وتقدير دو ال التكاليف في الاني 
Y. H. A. Ali

جدول رقم (1) : تطوركل من المساحة المزروعة والإنتاجية الفدانية والاتتاج الكلي لمحصول قصب السكر في مصر خلال

\begin{tabular}{|c|c|c|c|c|}
\hline & & \multicolumn{3}{|c|}{ الفترة (1995 - 2012 ). } \\
\hline سعر الطن بالجنية & الألفتاج طن) الكلى & انتاجية (لفدان & (ألف فـاحة) & السنوات ل \\
\hline 90 & 14104.77 & 46.02 & 306.48 & 1995 \\
\hline 90 & 13958.41 & 46.53 & 299.99 & 1996 \\
\hline 95 & 13725.53 & 47.16 & 291.02 & 1997 \\
\hline 95 & 14352.78 & 49.24 & 291.46 & 1998 \\
\hline 95 & 15253.62 & 49.65 & 307.22 & 1999 \\
\hline 95 & 16030.28 & 49.53 & 323.62 & 2000 \\
\hline 95 & 15571.52 & 49.91 & 311.99 & 2001 \\
\hline 95 & 16030.28 & 49.53 & 323.63 & 2002 \\
\hline 105 & 16245.46 & 49.65 & 327.22 & 2003 \\
\hline 105 & 16334.76 & 49.92 & 327.22 & 2004 \\
\hline 130 & 16319 & 50.77 & 321.43 & 2005 \\
\hline 160 & 16658.1 & 50.95 & 326.95 & 2006 \\
\hline 160 & 17013.53 & 50.77 & 335.11 & 2007 \\
\hline 200 & 16471.75 & 50.9 & 323.61 & 2008 \\
\hline 334.5 & 16019.93 & 48.88 & 327.74 & 2009 \\
\hline 335 & 18754.04 & 49.24 & 308.09 & 2010 \\
\hline 335 & 15397.92 & 49.51 & 311.01 & 2011 \\
\hline 335 & 15765.21 & 48.43 & 325.49 & 2012 \\
\hline 163.86 & 15778.16 & 49.26 & 316.07 & المثتوسط \\
\hline
\end{tabular}

المصدر : وزارة الزراعـة واستصـلاح الأراضسى ، قطاع الثئون الاقتصادية نثرة الاقتصاد الزراعى ، أعداد مختلفة .

جدول رقم (2): معادلات الاتجاه الزمنى العام تطوركل من المساحة المزروعة والإنتاجية|لفدانية والانتاج الكلي لمحصول

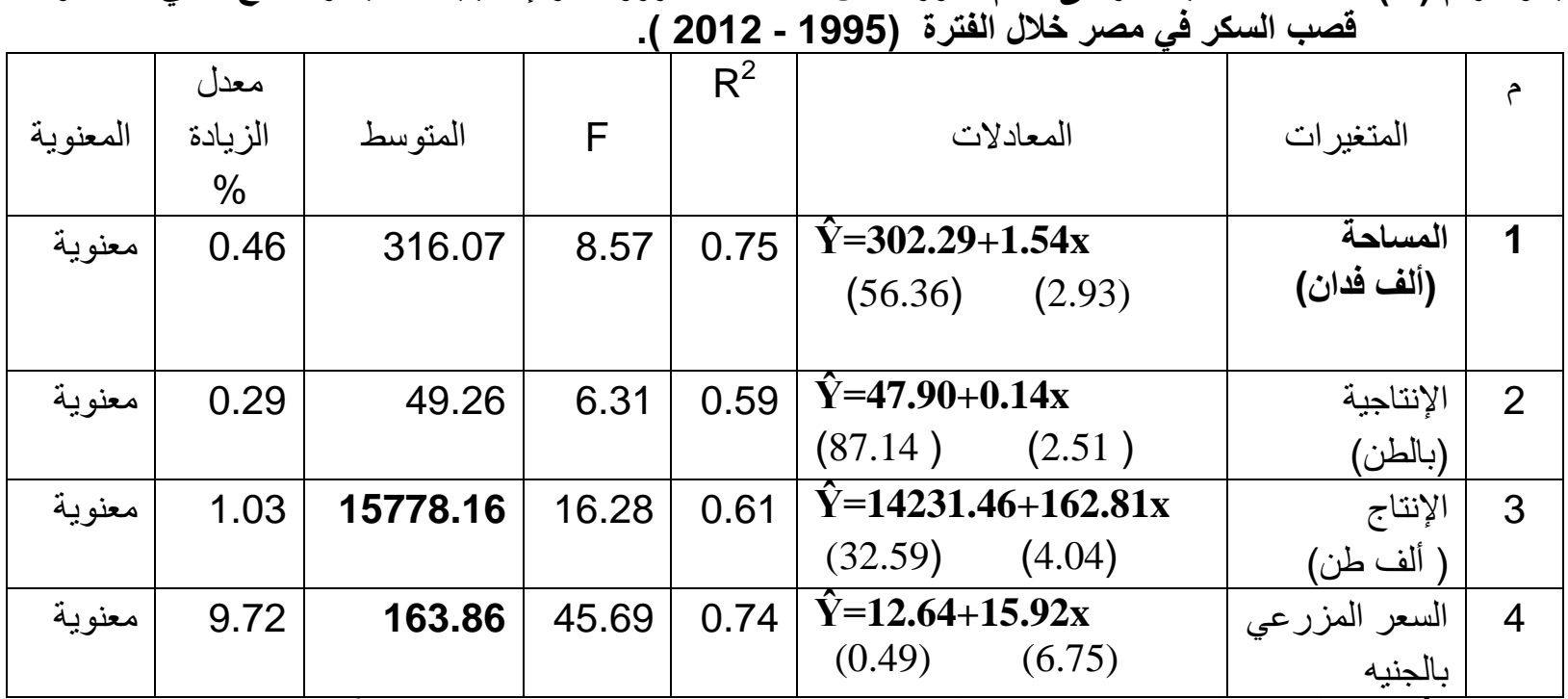

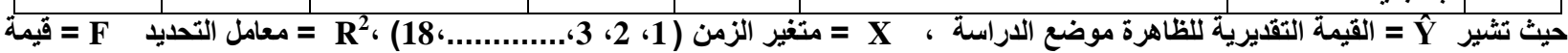

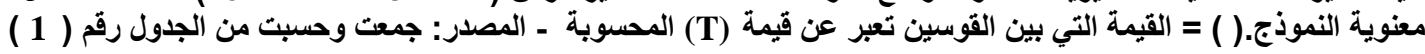

في عامي 1995، 1996 ،وحد اقصي بلغ نحو 335 جنية

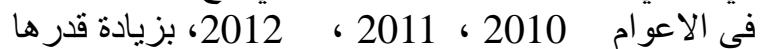

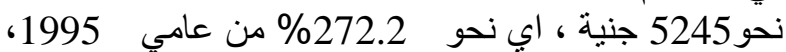

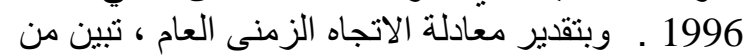

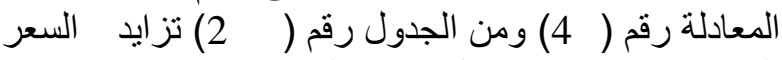
المزرعي من معصول مصن فصب السكر بمقدار معنوى
من المنوسط العام خلال فترة الدر اسة ، وقد بلغ معامل

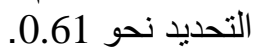
تطور السعر المزرعي يتضح من الجدول رَّم ( 1) الن المتوسط السنوي للسعر المزرعي لمحصول قصب السكر بلغ نحو 163.86 جنية المنية خلال الفترة(1995 - 2012) بحد ادني بلغ نحو 90 جنية 
جنية، بمعدل زيادة سنوي بلغ نحو 11.46\% من المتوسط العام خلال فترة الدراسة ، وقد بلغ معامل التحديد نحو

ربحية الجنيه المنفق فى الموسم

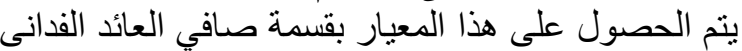

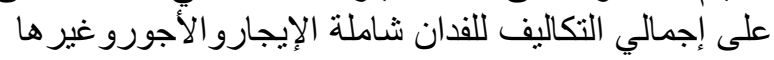
، وتعكس زيادة هذا المعيار وهو ارتفاع الكاع ربحية الجنيه

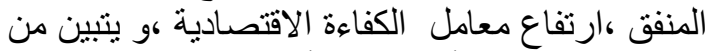

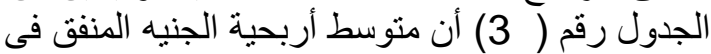
الموسم لمحصول القصب بلغ نحو

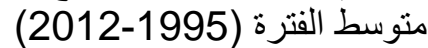
نسبة إجمالي الإيراد الكلى الى التكاليف الكلية

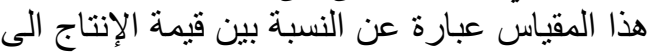

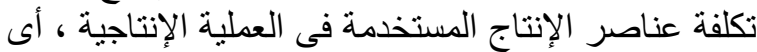

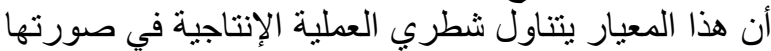

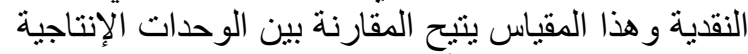

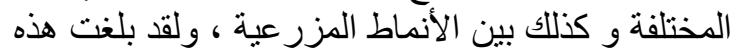

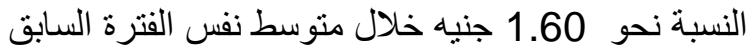

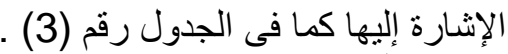

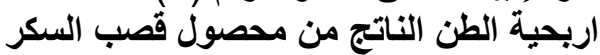
هذا المقياس عبارة عن النسبة بين قيمة الانتاجية الفدانية

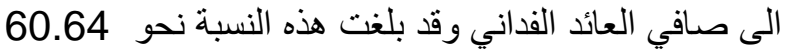
جنيه للطن خلال منوسط نفس الفترة السابق الإشارة إليها

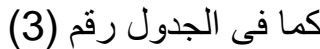

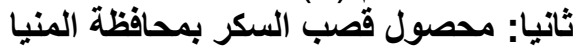
تطور المساحة المزروعة أهن الميكر

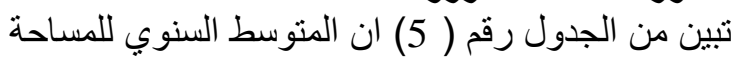
المزرو عة بمحصول قصب السكر في المنيا بلغ نحو 33.98 الف فدان خلال الفترة ( 1995 - 2012) بحد الفي في بلغ الفي نحو 21.22 الف فدان في عام 1997 ، ورحد اقصي بلغ إنغ نحو 39.49 في عامي

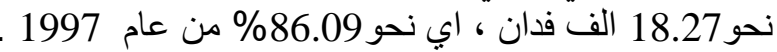
وبتقدير معادلة الاتجاه الزمنى العام ، تبين من المعادلة رعنة رقم

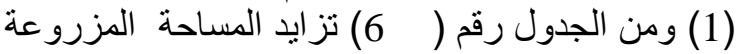
بمحصول قصب السكر بمقدار معنوى إحصائيا بلغ نحو النو

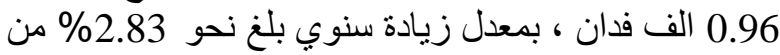

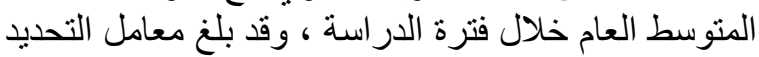
تطور الانتاجية الفدانية

تبين من الجدول رقم ( 5) ان المنتوسط السنوية السنوي للانتاجية الفدانية لمحصول قصب الجناب ليكر في المنيا بلغ نحو 48.36 طن خلال الفترة( 1995 - 2012) بحد ادني بلغ

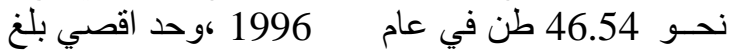

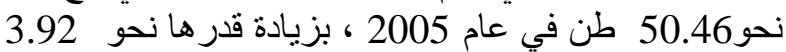

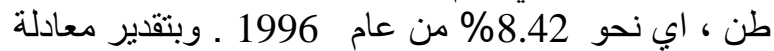

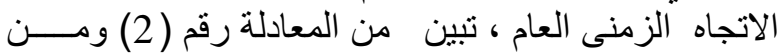

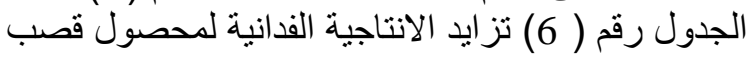

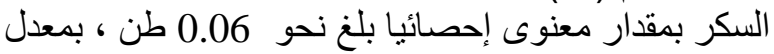

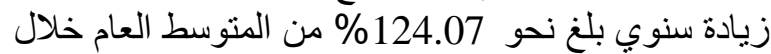
فترة الدر استة ، وقد بلغ معامل التحديد نحو 0.55.
إحصائيا بلغ نحو 15.92 جنية، بمعدل زيادة سنوي بلغ الحز نحو 9.72\% من المتوسط العام خلال فترة الدراسة ، وقدي ولد بلغ معامل التحديد نحو 0.74. مقاييس الكفاعة الاقتصادية لمحصول القصب في مصر ومحافظة المنيا :

يعد صافى العائد الفدانى من أهم العو امل الرئيسية

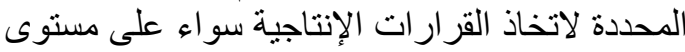

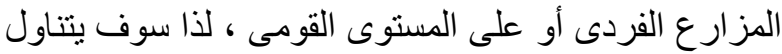

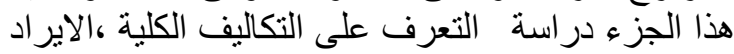

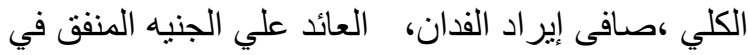

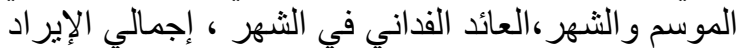
الكلى الى التكاليف الكلية للوقوف علي الكفاءة الاقتصادية اللكاية

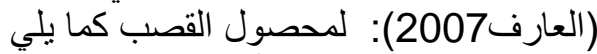
مقاييس الكفاءة الاقتصادية ل مصصول لمصب لمبل السكر في

\section{التكاليف الكلية}

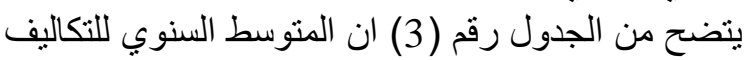

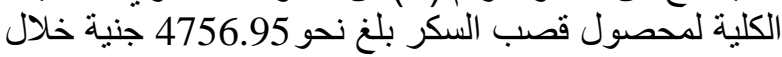
الفترة( 1995 - 2012) بحد ادني بلغ نحو 2661.6 جنية في عام 1995 ،وحد اقصي بلغ نحو 11443 جنية في عام النيا

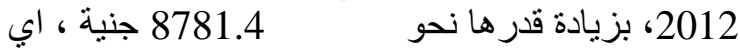
نحو 329.93\% من عام 1995 ـ وبتقدير معادلة الاتجاه

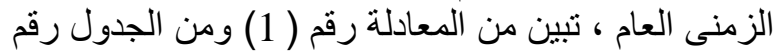

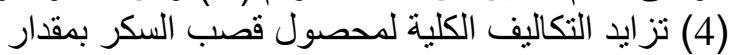

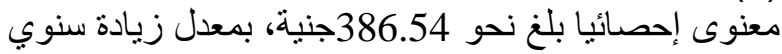

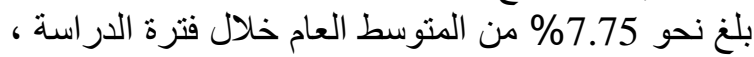

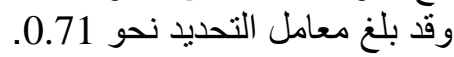
الايراد الكلي للفدان

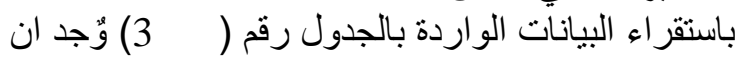

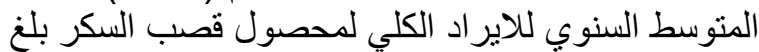

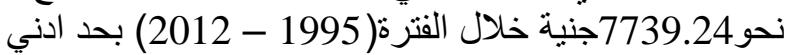
بلغ نحو 4141.8 جنية في عام 1995 ،وحد اقصي بلغ نحو

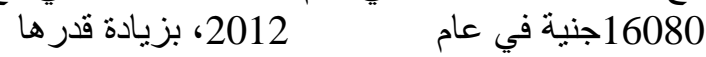

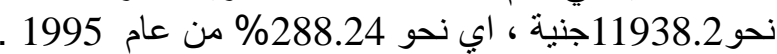

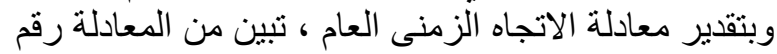

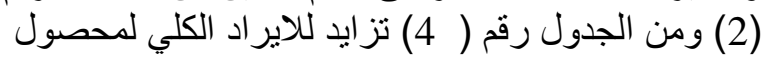
قصب السكر بمقدار معنوى إحصائيا بلغ نحو

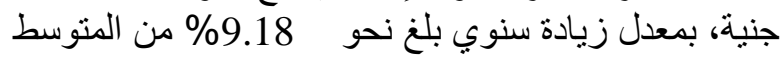
العام خلال فترة الدراسة ، وقد بلغ معامل التحديد نحو

\section{العائد الفداني}

باستقر اء البيانات الواردة بالجدول رقم ( 3) ان المبان المتوسط

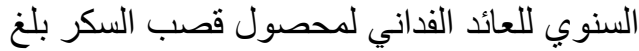

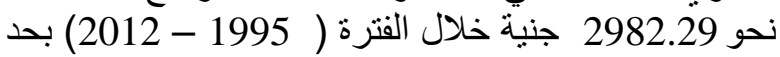
ادني بلغ نحو 1005.35 جنية في عام 2002 ،وحد الفي اقصي

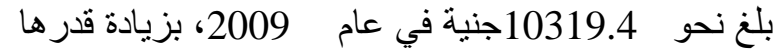

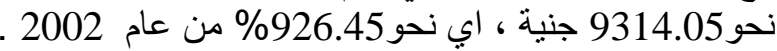
وبتقدير معادلة الاتجاه الزمنى العام ، تبين من المعادلة رئلة رقم

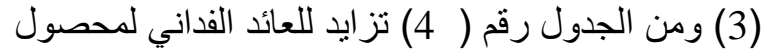
قصب السكر بمقدار معنوى إحصائيا بلغ نحو 
جدول رقم (3) : تظوركل من التكاليف الكلية والايراد الكلي وصافي العائد الفداني لمحصول قصب السكر في مصر خلال

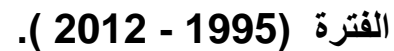

\begin{tabular}{|c|c|c|c|c|c|c|c|}
\hline 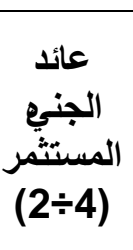 & ربحية & 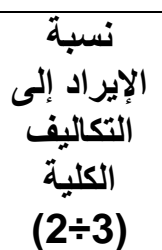 & 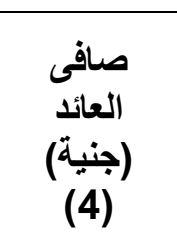 & (الإيليراد & قيمة التكاليف & $\begin{array}{c}\text { متوسط الإنتاج } \\
\text { (1) }\end{array}$ & السنوات \\
\hline 0.56 & 32.16 & 1.56 & 1480.2 & 4141.8 & 2661.6 & 46.02 & 1995 \\
\hline 0.54 & 31.48 & 1.54 & 1464.9 & 4187.7 & 2722.8 & 46.53 & 1996 \\
\hline 0.59 & 35.13 & 1.59 & 1656.6 & 4480.2 & 2823.6 & 47.16 & 1997 \\
\hline 0.34 & 24.36 & 1.34 & 1199.5 & 4677.8 & 3478.3 & 49.24 & 1998 \\
\hline 0.37 & 25.69 & 1.37 & 1275.35 & 4716.75 & 3441.4 & 49.65 & 1999 \\
\hline 0.29 & 21.49 & 1.29 & 1025.9 & 4535.3 & 3509.4 & 47.74 & 2000 \\
\hline 0.35 & 24.49 & 1.35 & 1222.45 & 4741.45 & 3519 & 49.91 & 2001 \\
\hline 0.27 & 20.3 & 1.27 & 1005.35 & 4705.35 & 3700 & 49.53 & 2002 \\
\hline 0.45 & 32.49 & 1.45 & 1613.25 & 5213.25 & 3600 & 49.65 & 2003 \\
\hline 0.27 & 22.25 & 1.27 & 1110.6 & 5241.6 & 4131 & 49.92 & 2004 \\
\hline 0.53 & 45.26 & 1.53 & 2298.1 & 6600.1 & 4302 & 50.77 & 2005 \\
\hline 0.85 & 73.41 & 1.85 & 3740 & 8152 & 4412 & 50.95 & 2006 \\
\hline 0.87 & 74.36 & 1.87 & 3775.2 & 8123.2 & 4348 & 50.77 & 2007 \\
\hline 0.8 & 89.19 & 1.8 & 4540 & 10180 & 5640 & 50.9 & 2008 \\
\hline 1.71 & 211.12 & 2.71 & 10319.4 & 16350.4 & 6031 & 48.88 & 2009 \\
\hline 1.04 & 137.6 & 2.04 & 6775.42 & 13319.4 & 6544 & 49.24 & 2010 \\
\hline 0.49 & 91.74 & 1.49 & 4542 & 13860 & 9318 & 49.51 & 2011 \\
\hline 0.41 & 95.75 & 1.41 & 4637 & 16080 & 11443 & 48.43 & 2012 \\
\hline 0.60 & 60.46 & 1.60 & 2982.29 & 7739.24 & 4756.95 & 49.26 & المتوسط \\
\hline
\end{tabular}

المصدر : وزارة الزراعــة واستصلاح الأراضى ، قطاع الثئون الاقتصادية ، نثرة الاقتصاد الزراعى ، أعداد مختلفة.

جدول رقم (4): معادلات الاتجاه الزمنى العام وتطوركل من التكاليف الكلية والايراد الكلي وصافي العائد الفاني لمحصول

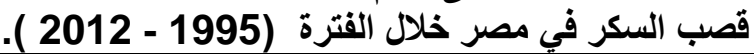

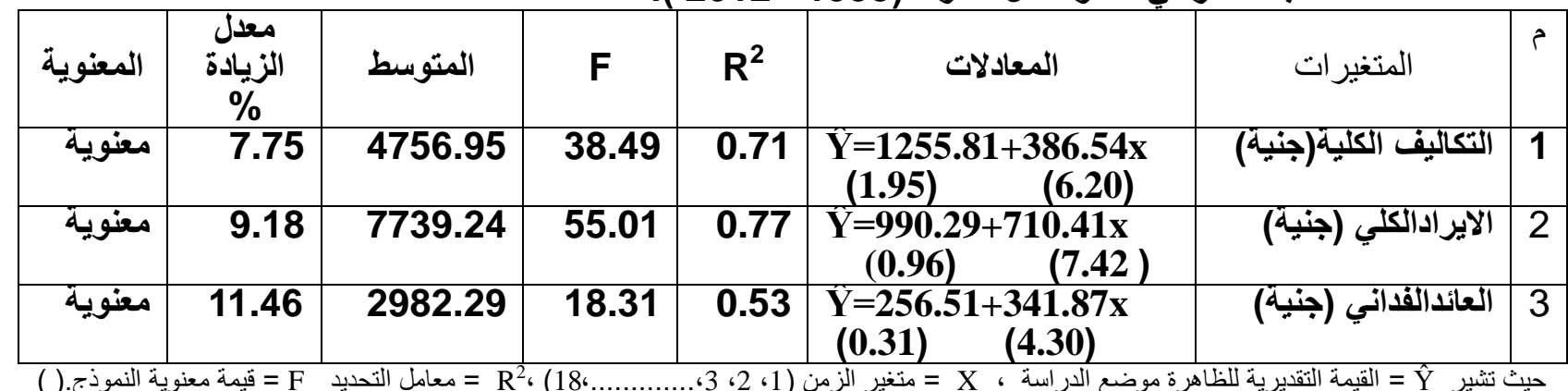

= القيمة التي بين القوسين تعبر عن قيمة (T) المحسوبة - المصدر : جمعت وحسبت من الجدول رقم ( 1 )

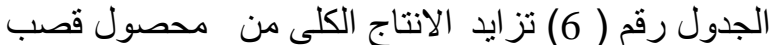
السكر بمقدار معنوى إحصائيا بلغ نحو

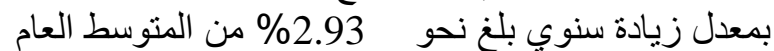

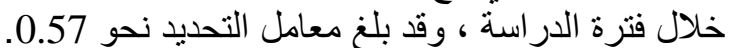
مقاييس الكفاءة الاقتصادية لمحصول فعلة قصب السكر بمحافظة المنيا

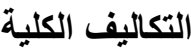
يتضح من الجدول رقم (7) ان المتوسط السنوي للتكاليف
تطور الانتاج الكلي

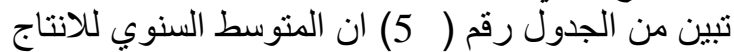

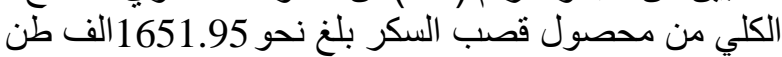

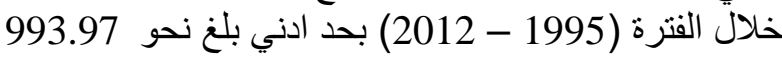

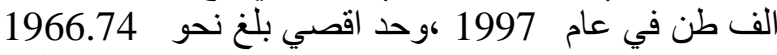

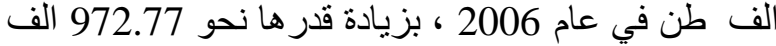

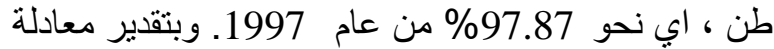
الاتجاه الزمنى العام ، تبين من المعادلة رقم ( 4) ومن 
جدول رقم(5) : تطوركل من المساحة المزروعة والانتاجية الفدانية والاتتاج الكلي لمحصول قصب السكر في محافظة

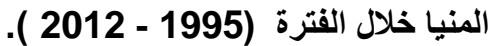

\begin{tabular}{|c|c|c|c|c|}
\hline (الجاري) الطن & ألأنت طن طن) & انتاجية الفدان & (ألف فداحة) & السنوات \\
\hline 90.00 & 1458.36 & 46.92 & 31.08 & 1995 \\
\hline 90.00 & 1344.80 & 46.54 & 28.89 & 1996 \\
\hline 95.00 & 993.97 & 46.83 & 21.22 & 1997 \\
\hline 95.00 & 1019.92 & 47.68 & 21.39 & 1998 \\
\hline 95.00 & 1243.64 & 46.44 & 26.77 & 1999 \\
\hline 95.00 & 1240.28 & 47.35 & 26.19 & 2000 \\
\hline 95.00 & 1655.13 & 49.75 & 33.26 & 2001 \\
\hline 95.00 & 1825.50 & 49.91 & 36.57 & 2002 \\
\hline 105.00 & 1915.30 & 50.29 & 38.08 & 2003 \\
\hline 105.00 & 1906.54 & 50.06 & 38.08 & 2004 \\
\hline 130.00 & 1943.20 & 50.46 & 38.50 & 2005 \\
\hline 160.00 & 1966.74 & 50.32 & 39.08 & 2006 \\
\hline 160.00 & 1957.76 & 49.57 & 39.49 & 2007 \\
\hline 200.00 & 1958.00 & 49.57 & 39.49 & 2008 \\
\hline 334.50 & 1825.79 & 49.26 & 37.06 & 2009 \\
\hline 335 & 1699.87 & 45.26 & 37.55 & 2010 \\
\hline 335 & 1903.16 & 46.72 & 39.48 & 2011 \\
\hline 335 & 1877.09 & 47.53 & 39.49 & 2012 \\
\hline 163.86 & 1651.95 & 48.36 & 33.98 & المتوسط \\
\hline
\end{tabular}

الصصدر : وزارة الزراعـة واستصـلاح الأراضى ، قطاع الثئون الاقتصادية ، الإدارة المركزية للاقتصاد الزراعى ، نثرة الاقتصاد الزراعى ، أعداد مختلفة . جدول رقم (6):معادلات الاتجاه الزمنى العام لتطوركل من المساحة المزروعة والإتتاجية الفانية والانتاج الكلي لمحصول قصب السكر لمرك

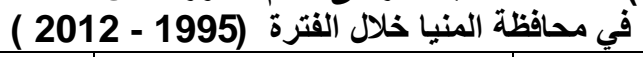

\begin{tabular}{|c|c|c|c|c|c|c|}
\hline المعنوية & الزيادة معدل & المتوسط & $\mathrm{F}$ & $\mathrm{R}^{2}$ & المعادلات & المتغير ات \\
\hline معنوية & 2.83 & 33.98 & 28.06 & 0.64 & $\begin{array}{c}\hat{\mathbf{Y}}=\mathbf{2 4 . 8 7 + 0 . 9 6 x} \\
(12.70) \quad(5.30)\end{array}$ & المساحة(ألف فدان) \\
\hline معنوية & 124.07 & 48.36 & 7.67 & 0.55 & $\begin{array}{l}\hat{\mathbf{Y}}=\mathbf{4 7 . 7 9}+\mathbf{0 . 0 6 x} \\
(56.64) \quad(2.77)\end{array}$ & الإنتاجية (بالطن) \\
\hline معنوية & 2.93 & 1651.95 & 21.41 & 0.57 & $\begin{array}{lc}\hat{\mathbf{Y}}=1192.25+48.40 x \\
(\mathbf{1 0 . 5 3}) & (4.63)\end{array}$ & الإتتاج ( ألف طن) \\
\hline
\end{tabular}

القوسين تعبر عن قيمة (T) المحسوبة - المصدر: جمعت وحسبت من الجدول رقم (5) (5)

محافظة المنيا بلغ نحو 7371.26 جنيه خلادل الفترة (1995 - 2012) بحد ادني بلغ نحو 4188.69 جنية في في عام 1996 ،وحد اقصي بلغ نحو 12058.2 جنية في عام نام 2012، بزيادة قدر ها نحو

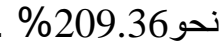
وبتقدير معادلة الاتجاه الزمنى العام ، تنين من المعادلة

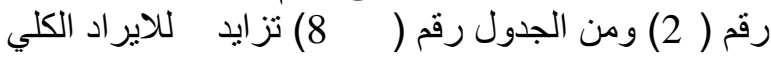

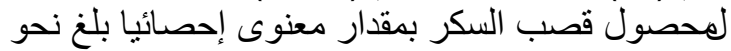

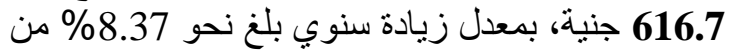
المنوسط العام خلال فترة الدر اسة وقد بلغ بلغ معامل التحديخ

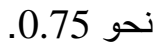

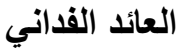

الكلية لمحصول قصب السكر في محافظة المنيا بلغ نحو 4447.78 جنية خلال الفترة ( 1995 - 2012) بحد في الفي ادني بلغ نحو 2518.10 جنية في عام 1995 ،وحد اقصي

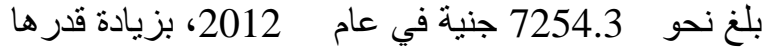

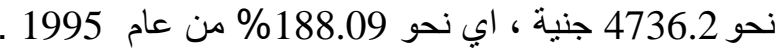
وبتقدير معادلة الاتجاه الزمنى العام ، تبين من المعادلة الئلة رقم

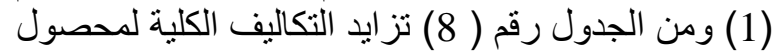
قصب السكر بمقدار معنوى إحصائيا بلغ نحو 278.17

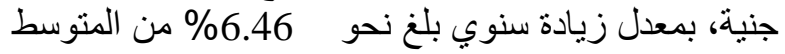
العام خلال فترة الدراسة ، وقد بلغ معامل التحديد نحو الحن 0.92

الايراد الكلي للفدان

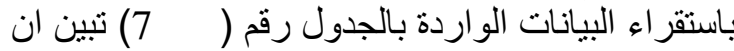
المتوسط السنوي للاير اد الكلي لمحصول قصب النب السكر في 
جدول رقم (7) : تطوركل من التكاليف الكلية والايراد الكلي وصافي العائد الفداني لمحصول قصب السكر في محافظة المنيا خلال

\begin{tabular}{|c|c|c|c|c|c|c|c|}
\hline & & & & & & & \\
\hline 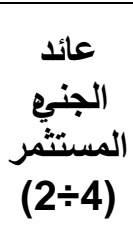 & ربحنة & 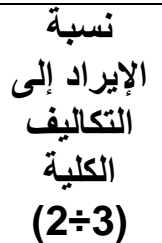 & العائدى & 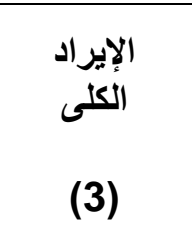 & قيمة التكاليف & $\begin{array}{c}\text { متوسط } \\
\text { الإنتاج) } \\
\text { (1) }\end{array}$ & السنوات \\
\hline 0.68 & 36.34 & 1.68 & 1705.24 & 4223.34 & 2518.10 & 46.93 & 1995 \\
\hline 0.62 & 34.58 & 1.62 & 1609.19 & 4188.69 & 2579.50 & 46.54 & 1996 \\
\hline 0.75 & 40.84 & 1.75 & 1912.55 & 4448.85 & 2536.30 & 46.83 & 1997 \\
\hline 0.42 & 28.22 & 1.42 & 1345.30 & 4529.60 & 3184.30 & 47.68 & 1998 \\
\hline 0.32 & 22.80 & 1.32 & 1059.06 & 4412.56 & 3353.50 & 46.45 & 1999 \\
\hline 0.33 & 23.60 & 1.33 & 1117.25 & 4498.25 & 3381.00 & 47.35 & 2000 \\
\hline 0.45 & 29.40 & 1.45 & 1463.11 & 4727.11 & 3264.00 & 49.76 & 2001 \\
\hline 0.25 & 19.11 & 1.25 & 953.83 & 4741.83 & 3788.00 & 49.91 & 2002 \\
\hline 0.34 & 26.84 & 1.34 & 1349.77 & 5280.77 & 3931.00 & 50.29 & 2003 \\
\hline 0.31 & 24.58 & 1.31 & 1230.62 & 5256.62 & 4026.00 & 50.06 & 2004 \\
\hline 0.48 & 41.90 & 1.48 & 2114.49 & 6560.45 & 4445.96 & 50.46 & 2005 \\
\hline 0.70 & 66.04 & 1.70 & 3323.62 & 8052.16 & 4728.54 & 50.33 & 2006 \\
\hline 0.53 & 55.76 & 1.53 & 2764.20 & 7931.20 & 5167.00 & 49.57 & 2007 \\
\hline 0.76 & 86.24 & 1.76 & 4275.20 & 9915.20 & 5640.00 & 49.58 & 2008 \\
\hline 1.38 & 194.03 & 2.38 & 9558.54 & 16478.14 & 6919.60 & 49.26 & 2009 \\
\hline 0.71 & 112.66 & 1.71 & 5098.83 & 12242.83 & 7144.00 & 45.26 & 2010 \\
\hline 0.97 & 129.24 & 1.97 & 6037.88 & 12236.9 & 6199.02 & 46.72 & 2011 \\
\hline 0.79 & 120.01 & 1.79 & 5703.9 & 12958.2 & 7254.3 & 47.53 & 2012 \\
\hline 0.61 & 60.59 & 1.61 & 2923.48 & 7371.26 & 4447.78 & 48.36 & المتوسط \\
\hline
\end{tabular}

جدول رقم (8) : معادلات الاتجاه الزمنى العام لتطوركل من التكاليف الكلية والايراد الكلي وصافى العائد الفدانيلمحصول قصب السكر في محافظة المنيا خلال الفترة (1995 - 2012 ).

\begin{tabular}{|c|c|c|c|c|c|c|}
\hline المعنوية & 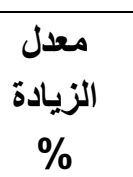 & المتوسط & $F$ & $\mathbf{R}^{2}$ & المعادلات & المتغيرات \\
\hline معنوية & 6.46 & 4447.78 & 184.42 & 0.92 & $\begin{array}{c}\hat{\mathbf{Y}}=\mathbf{1 7 1 9 . 6 6 + 2 7 8 . 1 7 x} \\
(7.51)\end{array}$ & (جنية) التيف الكلية \\
\hline معنوية & 8.37 & 7371.26 & 47.86 & 0.75 & $\begin{array}{l}\hat{\mathbf{Y}}=\mathbf{1 5 1 2 . 6 1 + 6 1 6 . 7} \quad x \\
(\mathbf{1 . 5 7 )} \quad(6.92)\end{array}$ & $\begin{array}{r}\text { (الاير ادالكلية) } \\
\text { (جنية) }\end{array}$ \\
\hline معنوية & 11.27 & 2923.48 & 20.50 & 0.56 & $\begin{array}{l}\hat{\mathbf{Y}}=\mathbf{2 0 7 . 0 5 + 3 2 9 . 5 3 x} \\
(0.261)\end{array}$ & $\begin{aligned} \text { العائدالفدانية) } \\
\text { (جنية) }\end{aligned}$ \\
\hline
\end{tabular}

النموذج.( ) = القيمة التي بين القوسين تعبر عن قيمة (T) المحسوبة ـ المصدر: جمعت وحسبت من الجدول رقم ( 7 )

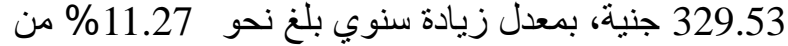

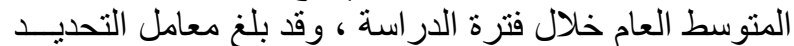

0.56

ربحية الجنية المنفق فى الموسم

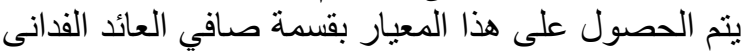

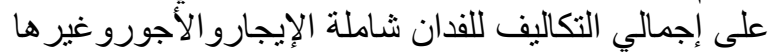

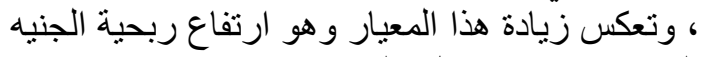

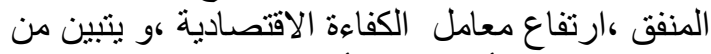
الجدول رقم(7) أن متوسط أربحية الجنيه المنفق فى الموسم

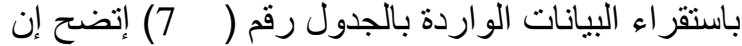

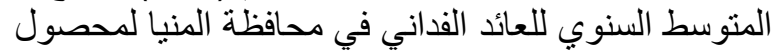

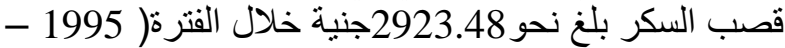
2012) بحد ادني بلغ نحو 953.83 جنية في عام 2002

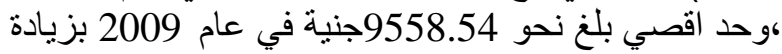

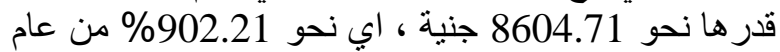

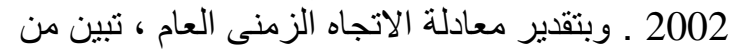

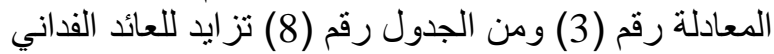

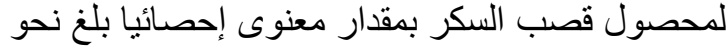


جنيها للفدان وبذللك تفوقت الفئة الحيازية الاولى فى التكاليف

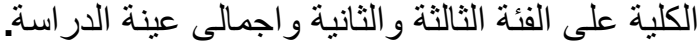

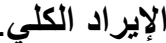
يتضح من الجدول ( 9) ان الفئة الحيازية الثالثة " ثلاثثة

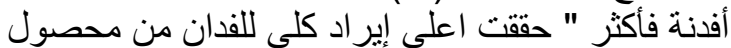

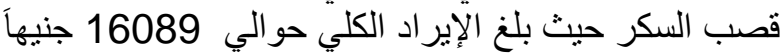

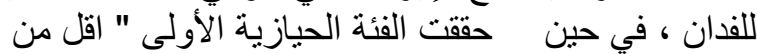

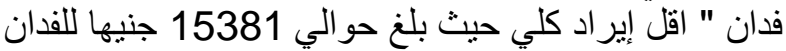
، وقد بلغ الإير اد الكلي لعينة الدراسة حو الي التي 15785 جنيهاً

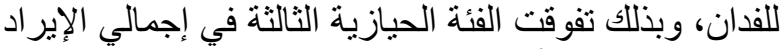

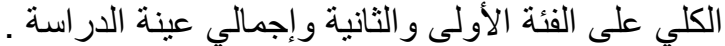
تكلفة إنتاج الطن يتضح من الجدول (10) ان الفئة الحيازية الثالثة " ثلاثنة

أفدنة فأكثر " قد حققت اقل تكلفة إنتاج لطن القصب حيث الفي

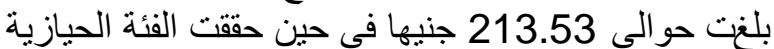

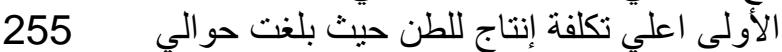

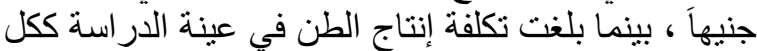
حو الي 231.64 جنيها وبذلك تفوقت الفئة الحيازية الثالثة الثية على الفئة الأولى و الثانية و اجمالي العينة في تقليل تكلفة إنتاج الطن ويرجع ذللك إلى كبر حجم الحياز ات للفئة الثالثة.

بتضح من الجدول ( 10) أن نسبة تكلفة إنتاج الطن إلى إلى إلى

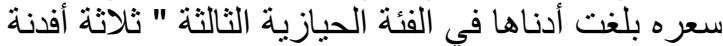

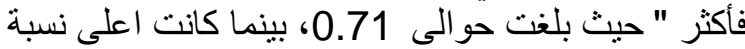

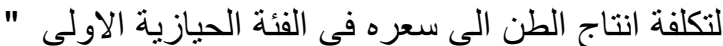

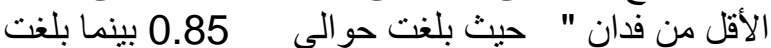
تكلفة إنتاج الطن إلى سعره بالنسبة لإجمالي العينة حو الي 0.77 وبذللك تفوقت الفئة الحبازية الثالثة على الأولى الثي

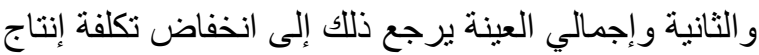

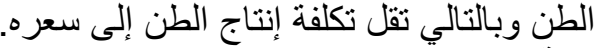
نسبة الإيراد الكلي إلى التكاليف المتغيرة

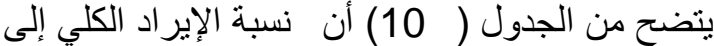

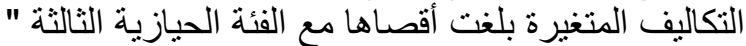

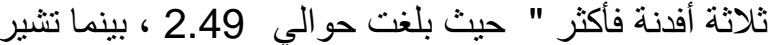

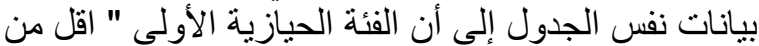

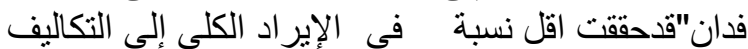

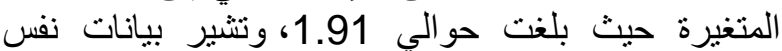

الجدول إلى أن نسبة الإير اد ألكلي إلى التكاليف التئغيرة

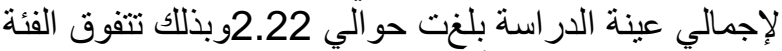

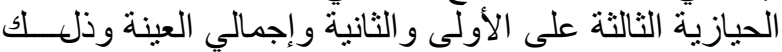
لأنه كلما زاد الإنتاج يزداد الإير اد الكلي فتزيد نسبة الإيراد الئل
لمحصول القصب بلغ نحو 0.61 جنيه خلال متوسط الفترة . 2012-1995)

نسبة إجمالي الإيراد الكلى الى التكاليف الكلية

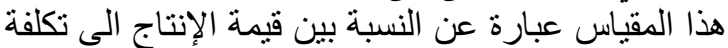

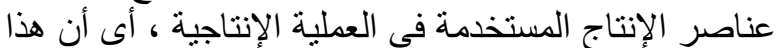
المعيار يتناول شطري العملية الإنتاجية في صورتها الإنتانية النقدية الإنية و هذا المقياس يتيح المقارنة بين الوحدات الإنتاجية المختلفة الإنية

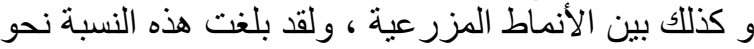
1.61 جنيه خلال منوسط نفس الفترة السابق الإشارة إليها

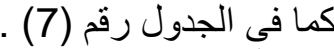
اربحية الطن الناتج من محصول قصب الجي السكر

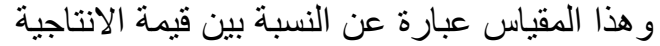

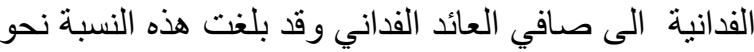
60.59 جنيه للطن خلال منوسط نفس الفترة السابق الفان

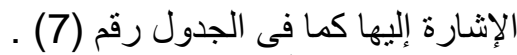

الكفاءة الاثتصادية لمحصول قصب الكبارية السكر في عينة الاراسة

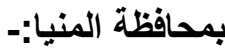

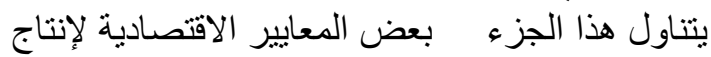

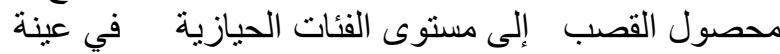

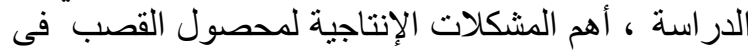
عينة الدر اسة بمحافظة المنيا كما يلي : متوسط إنتاج الفدان

ايتبين من الجدول ( 9) ان ان الفئة الحيازية الثالثة " ثلاثة

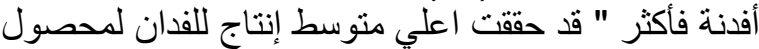
قصب السكر حيث بلغ متوسط الإنتاج حو الي 53.63 طناً

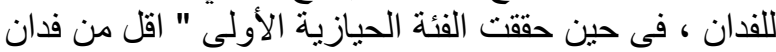

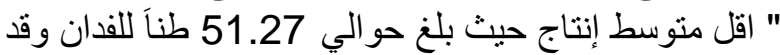

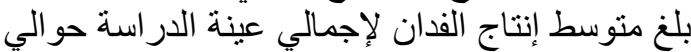
52.62 طنا للفدان وبذللك تفوقت الفئة الحيازية الثالثة على الثي الفئة الأولى و الثانية وإجمالي عينة الدئية الدراسة .

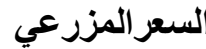
يتضح من الجدول ( 9) ثبات السعر المزرعي بالجنيه لطن قصب السكر في الفئات الحيازية الثناثثة وكذللك في إجمالي التي عينة الدر اسة حيث بلغ حو الي 300 جنيها للطن حيث النه النه سعر التوريد للمصنع. التكاليف المتغيرة

يتبين من الجدول (9) أن إجمالي التكاليف المتغيرة بلغت

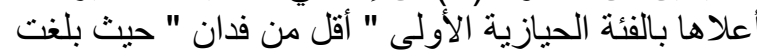

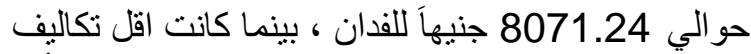
إجمالية متغيرة للفدان في الفئة الحيازية الثالثة " ثلاثثة أفدنة

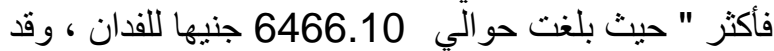

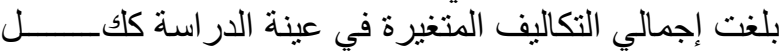
حو الي 7175.33 جنيها للفدان .

التكاليف الكلية

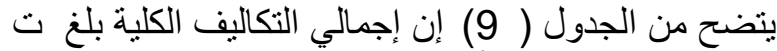

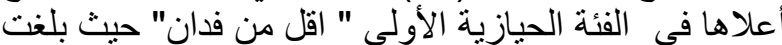
حو الي 13073.81 جنيهاً للفدان ، بينما كانت اقل التل تكلفة إجمالية

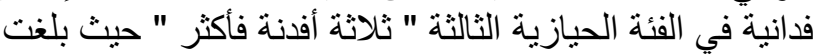

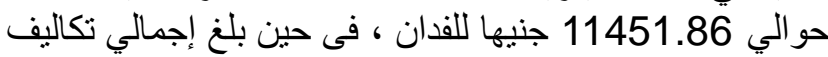
إنتاج فدان قصب السكر في العينة ككل حو الي 12171.01 


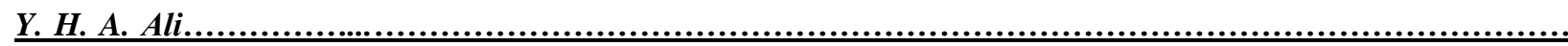

جدول (9) : مؤشرات الكفاعة الاقتصادية لمحصول قصب السكر على مستوى الفئات الحيازية للعينة بمحافظة المنيا خلال الموسم الزراعى2012/2011.

\begin{tabular}{|c|c|c|c|c|c|c|}
\hline الإيراد الكلى & التكاليف الكلية & التكاليف & المزرعى (بالجنيه) & الفدان (الطن إنتاج) & مساحة الفئة & الفئات \\
\hline 15381.00 & 13073.81 & 8071.24 & 300 & 51.27 & 0.58 & الفئة الأولى \\
\hline 15885.00 & 11987.35 & 6988.66 & 300 & 52.95 & 1.78 & الفئة الثانية \\
\hline 16089.00 & 11451.86 & 6466.10 & 300 & 53.63 & 4.38 & الفئة الثالثة \\
\hline 15785.00 & 12171.01 & 7175.33 & 300.00 & 52.62 & 2.25 & إجمالى العينة \\
\hline
\end{tabular}

المصدر:- جمعت وحسبت من استمارة الاستبيان .

جدول (10) : مؤشرات الكفاءة الاقتصادية لمحصول قصب السكر على مستوى الفئات الحيازية والعينة بمحافظة المنيا خلال الموسم

\begin{tabular}{|c|c|c|c|c|c|c|}
\hline \multicolumn{7}{|c|}{ الزراعى 2012/2011. } \\
\hline عائد الجنياه & 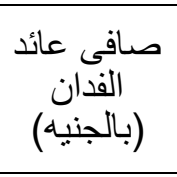 & نسبة الإير اد التكلي ألكلية & الكبة الإِير اد التكاليف & الطنة أنتاج تكلفة & 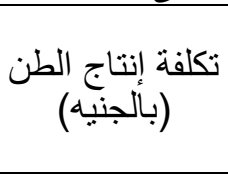 & الفئات \\
\hline 0.18 & 2307.19 & 1.18 & 1.91 & 0.85 & 254.99 & الفئة الأولى \\
\hline 0.33 & 3897.65 & 1.33 & 2.27 & 0.75 & 226.39 & الفئة الثانية \\
\hline 0.40 & 4637.14 & 1.40 & 2.49 & 0.71 & 213.53 & الفئة الثالثة \\
\hline 0.30 & 3613.99 & 1.30 & 2.22 & 0.77 & 231.64 & إجمالى العينة \\
\hline
\end{tabular}

جدول(11) : المساحة المزروعة لمحصول قصب السكر بمراكز محافظة المنيا بالفدان خلال الفترة (2008 / 2010-2009 / 2011)

\begin{tabular}{|c|c|c|c|c|}
\hline المساحة بالفدان & $2011 / 2010$ & 2010 / 2009 & 2009 / 2008 & المر اكر السنة \\
\hline 14.7 & 22 & 22 & - & العدوة \\
\hline 147.4 & 141 & 141 & 160 & مغاغة \\
\hline 167.7 & 145 & 143 & 215 & بني مزار \\
\hline 29.4 & 26 & 27 & 35 & مطابي \\
\hline 188.4 & 255 & 60 & 250 & سمالوط \\
\hline 950.4 & 890 & 939 & 1022 & المنيا \\
\hline 5607.7 & 5704 & 5330 & 5789 & ابوقرقاص \\
\hline 20388.7 & 20838 & 20472 & 19856 & ملوي \\
\hline 10569.4 & 10738 & 10429 & 10541 & دير مواست \\
\hline 38066.7 & 38769 & 37563 & 37868 & الاجمالي \\
\hline
\end{tabular}


المركز ان هما مركز ملوى حيث تبلغ متوسط مساحة القصب

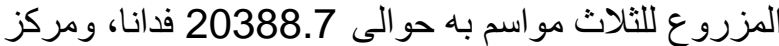

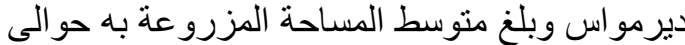

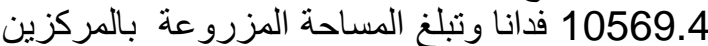

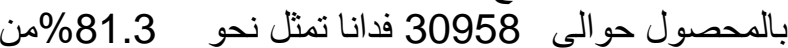

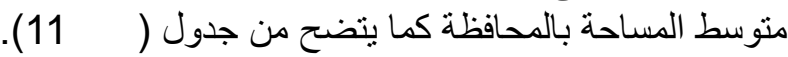

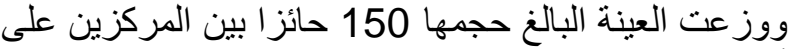

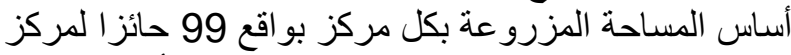

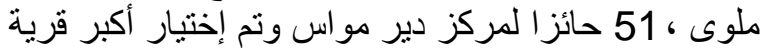

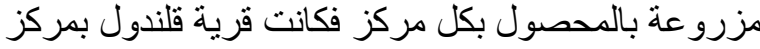

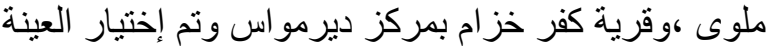

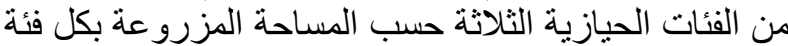
وذللك على النحو التالى :

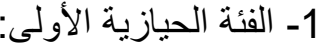

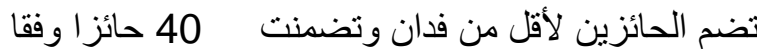
لمساحة هذه الفئة بالقرينتين

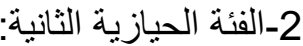
وتضم الحائزين من فدان إلى أقل من ثلاث أفدنة فكانت 51

3-الفئة الحيازية الثالثة:

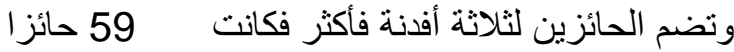

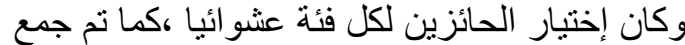
البيانات عن طريق المقابلة الشخصية للحائزين في نهاية الموسم الزراعى 2010.

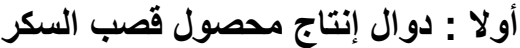

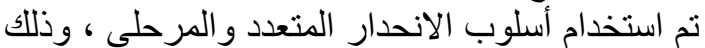

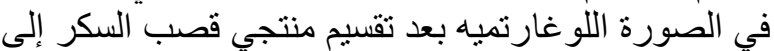

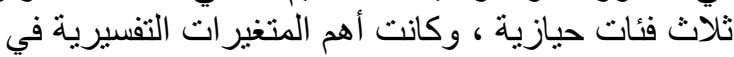

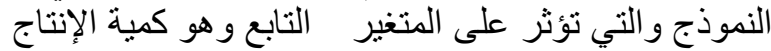

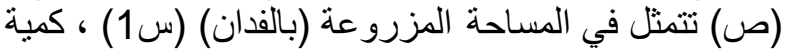

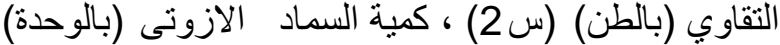

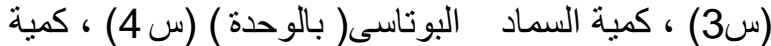

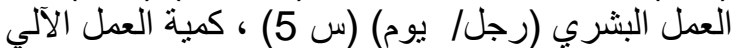

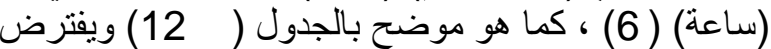

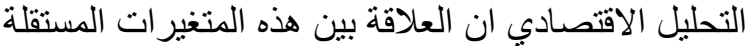

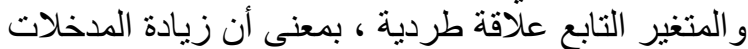

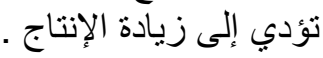

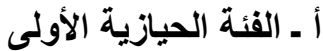
يثبين جدول رقم (12) والتي تمثل دالة الإنتاج الفيزيقية

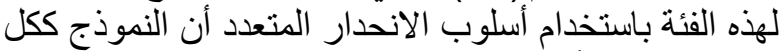

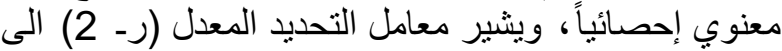

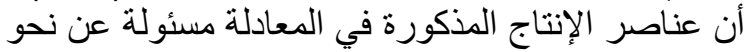

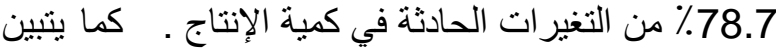

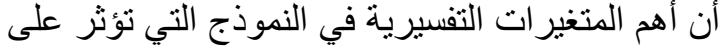

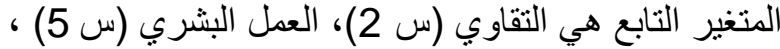

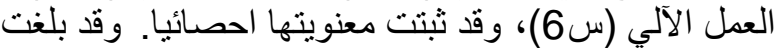

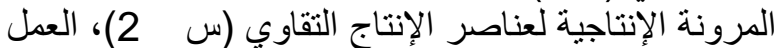

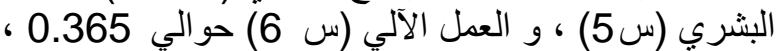
0.104 ، 0.362 على الترتيب مما بعني الني زي زيادة
الكلي إلى التكاليف المتغيرة . نسبة الإيراد الكلي إلى التكاليف الكلية

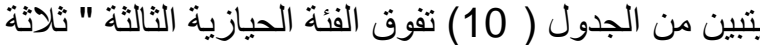

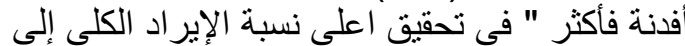

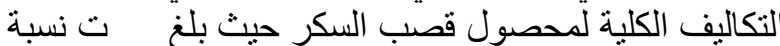
الإير اد الكلي إلى التكاليف الكلية حو الي 1.4 ، بلينما لإلي حققت الفئة الحيازية الأولى اقل نسبة إلاير اد الكلي إلى التئلئل التكاليف

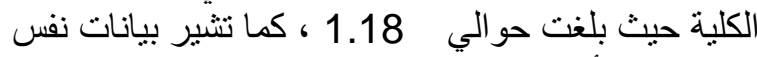
الجدول إلى أن نسبة الإير اد الكلي إلى التكاليف الكلية

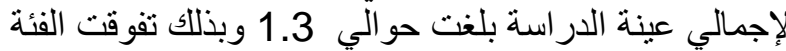

الحيازية الثالثة على الفئة الأولى و الثانية و إجمالي عينة

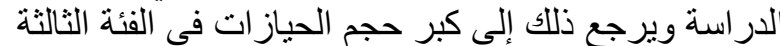
فكلما زاد حجم الحيازة كلما زاد الإنتاج وز الدير الإير اد الكياد الكلي فتزيد نسبة الإير اد الكلي إلى التكاليف الكلية

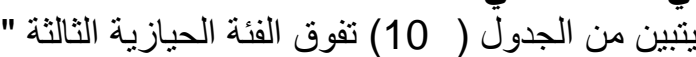

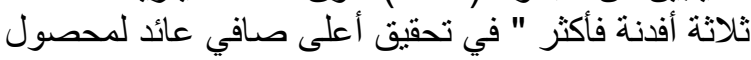

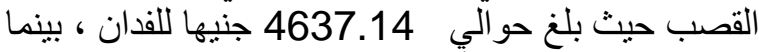
حققت الفئة الحيازية الأولى " اقل من فدان " اقل صافي

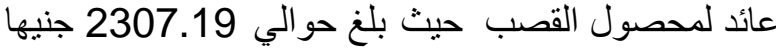

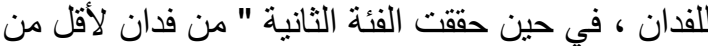

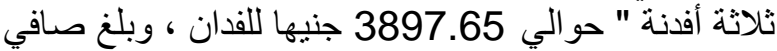
عائد الفدان في إجمالي العينة حو الي 365 الفئية 3613.99 جنيها للفذان ويرجع تفوق الفئة الحيازية الثالثة على الفئة الأولى الثي

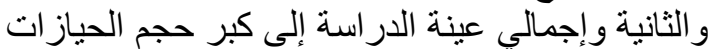

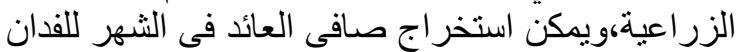

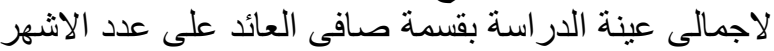

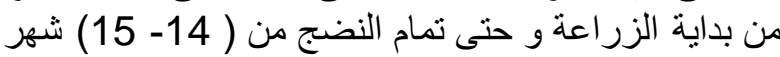
حيث بلغت حو الى الى 258.14جنئهيا

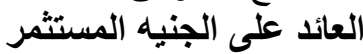

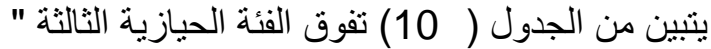

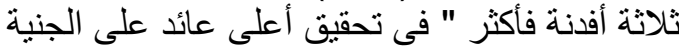

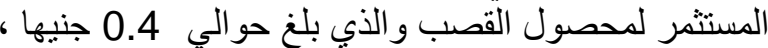

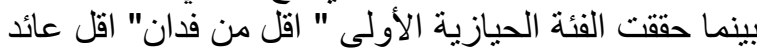
على الجنيه المستثمر حيث بلغ حوالية الألي 0.18 جنيها ، في في حين حققت الفئة الحيازية الثانية " من فدان لأقل من ثيلاثة

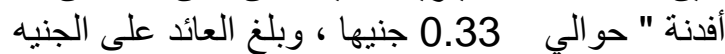

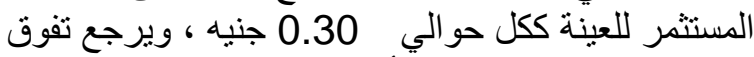

الفئة الحيازية الثالثة على الأولي و الثانية و إجمالي عينة

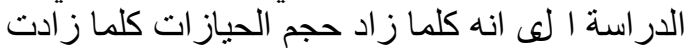

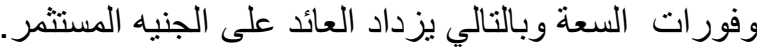

ثانيا : التقدير الاحصائى لاوال إنتاج وتكاليف محصول قصب السكر بمحافظة المنيا لإلياج

يتم تقدير دو ال الإنتاج و التكاليف على مستوى المنافيات الفئات الحيازية كل على حده في عينة الدر اسة بالمحافظة ، ولئة وكيفية اختيار العينة الميدانية. اختيار عينة الدراسة اليدانة

تم اختبار أكبر مركزين من حيث المراسئ المساحة المزروعة

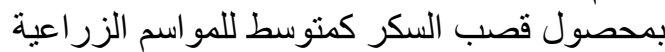
2009/2008، 2010/2009 ، 2011/2010، وكان الزيكر 
بلغت المرونة الإنتاجية لعناصر المساحة المزروعة (سل) العاد)

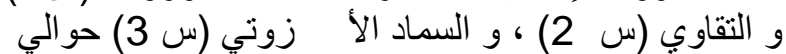

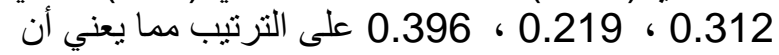

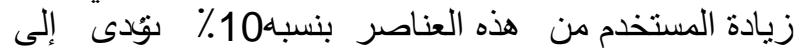

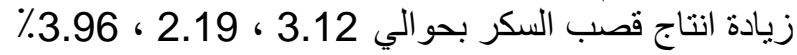

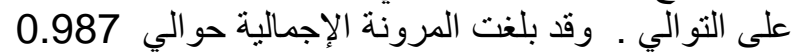

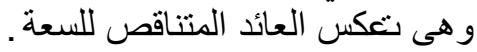
د ـ ـ إجمالي عينة الاراسة

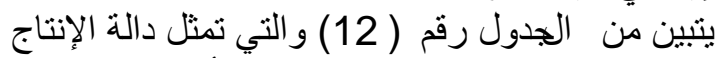
الفيزيقية لإجمالي عينة الدر اسة باستخدام أسلوب العين الانحدار

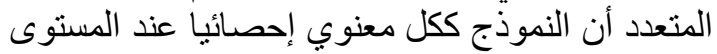

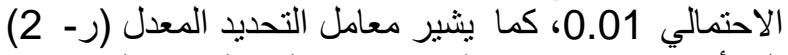

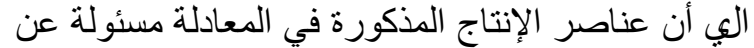

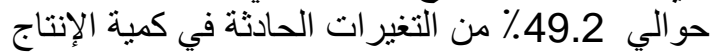

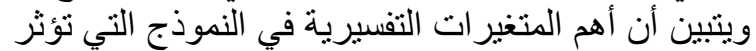

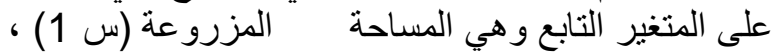

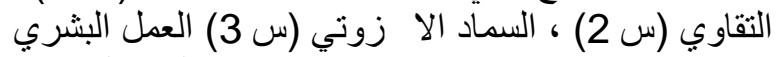

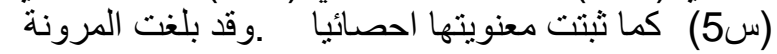

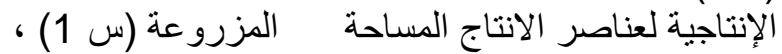

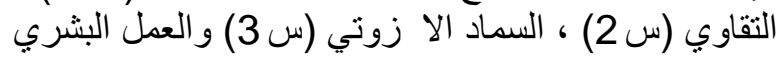
(س5) حوالي 0.036 ، 0.401 ، 0.407 ، 0.067 ، 0.076 على الترتيب مما بعني ان الزيادة المستخدمة من هذه

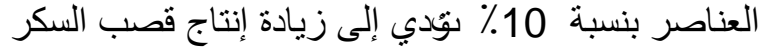

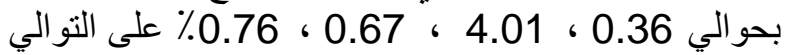

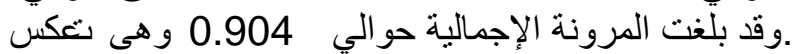

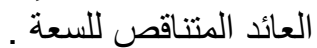

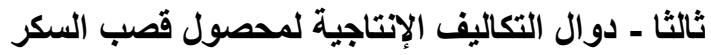

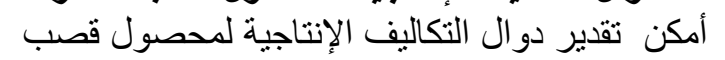
السكر في عينة الدر اسة وذللك باستخدام التكاليف الإنتاجية الإنية

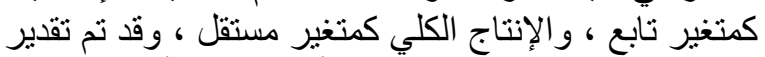

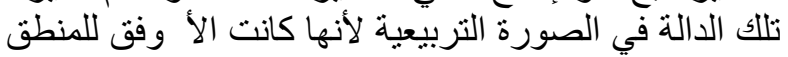

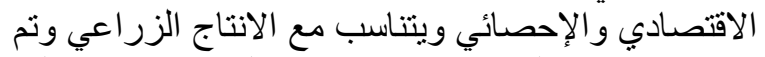
تقدير مؤشرات الكفاءة الإنتاجية وهي الحجم الإنتاجي الذي الذي
المستخدم من هذه العناصر بنسبة 10\% تؤدي إلى زيادة

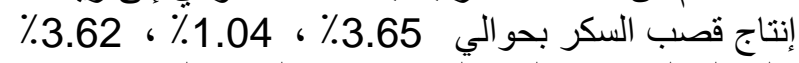

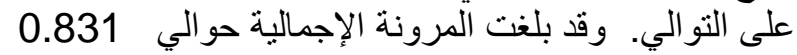

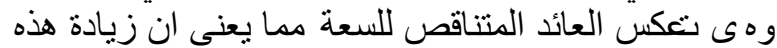

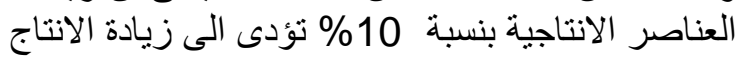

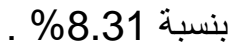
ب ب الفئة الحيازية الثانية يتبين جدول رقم (12) و التي تمثل دالة الإنتاج الفيزيقية

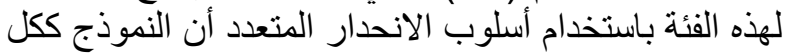

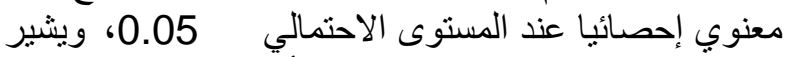

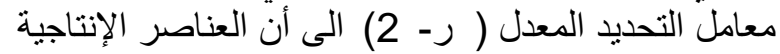

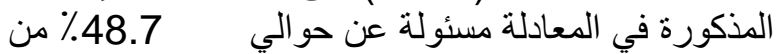

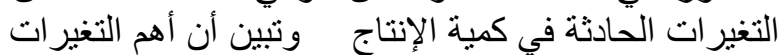

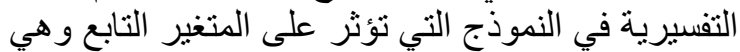

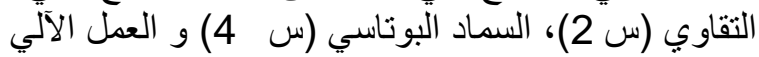

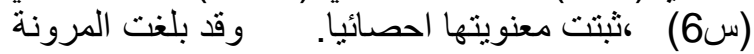
الإنتاجية لعناصر الإنتاج التقاوي (س 2) و و السماد الازونى العيا.

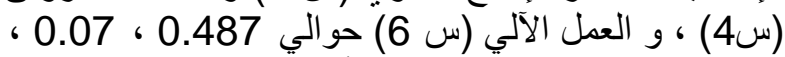

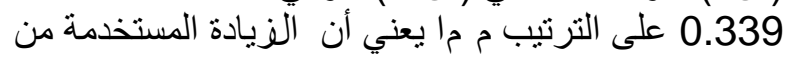

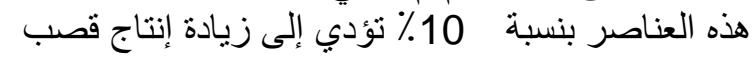

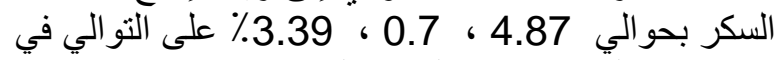

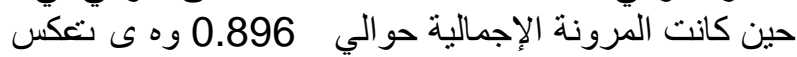

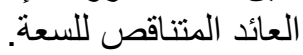
ج - الفئة الحيازية الثالثة

تبين من الجدول رقم (12) والتي تمثل دالة الإنتاج

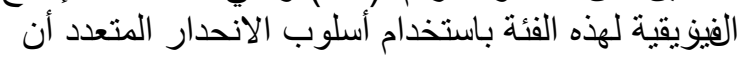

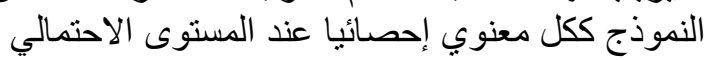

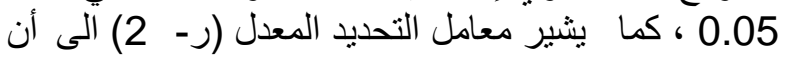

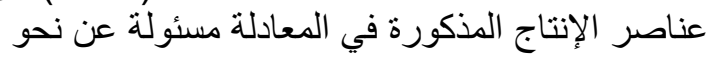

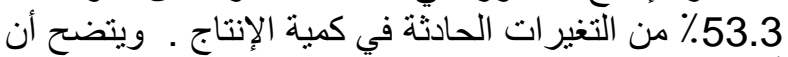

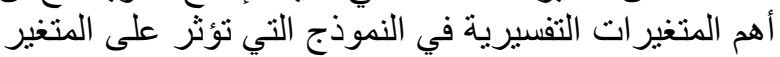

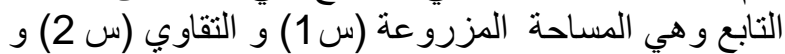
السماد الأزوتي (س 3) وقد ثبتت معنويتهم احصنائيا. وقد

جدول (12) : التقدير الإحصائي للاوال الإنتاجية لمحصول قصب السكر بمحافظة المنيا للفلئ الحيازية خلال الموسم الزراعى 2012/2011.

\begin{tabular}{|c|c|c|c|c|}
\hline الإجمالية & قيمة (ف) & 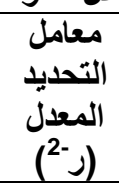 & الدالة الإنتاجية الفيزيقية بصورتها اللوغاريتمية & رقم المعادلة \\
\hline 0.831 & **49.06 & 0.787 & 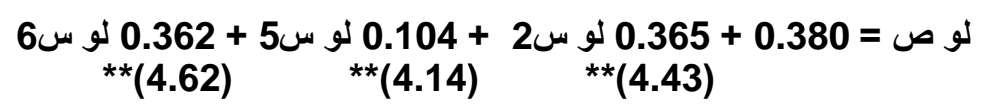 & الفئة الحيازية \\
\hline 0.896 & **9.06 & 0.487 & 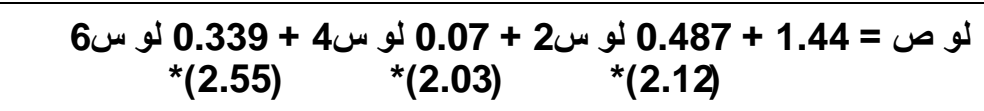 & الفئة الحيازية \\
\hline 0.927 & $* * 23.06$ & 0.533 & 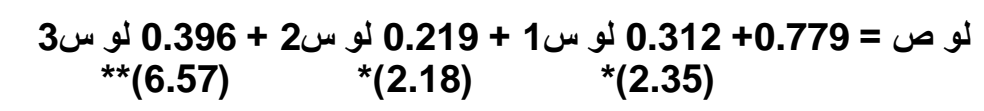 & الفئة الحيازية الثالثة \\
\hline 0.904 & **37.14 & 0.492 & 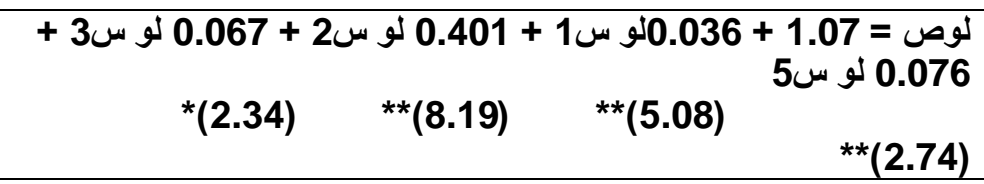 & اجمالي العينة \\
\hline
\end{tabular}

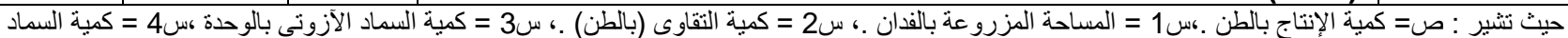
البوتاسى بالوحدة .، س5 = كمية العمل البشرى (رجل لوبوم) . ، س6 = كمية العمل الآلى (ساعة) . المصدر : جمعت وحسبت من استمارة الاستبيان . 
التكاليف حو الي 50.89 طنا وقد حقق هذا الحجم 37 العن 3

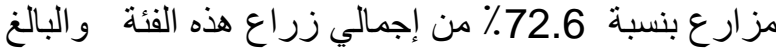

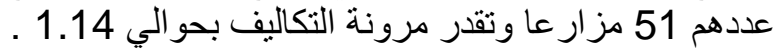
ج - بالنسبة للفئة الحيازية الثالثة يتضح من الجدول رقم (13) أنسالنة الدالة المقدرة معنوية إحصائيا وتشير قيمة (ر- 2 2) معامل التحديد المعدل إلى أن أن النية

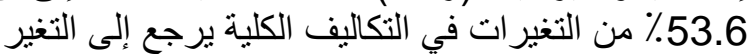

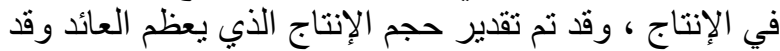

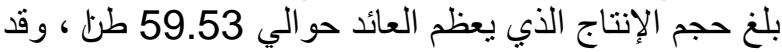
حقق عدد انثين من زراع هذه الفئة هذا الحجم من الإنتاج

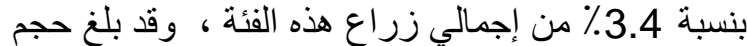
الإنتاج الذي يدنى منوسط التكاليف حو الي 53.07 طن الن وقد

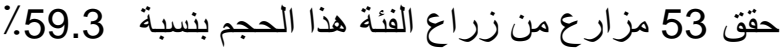

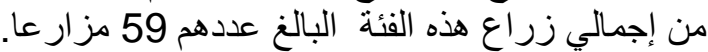

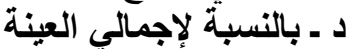

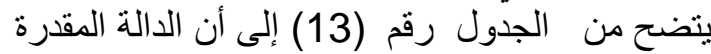

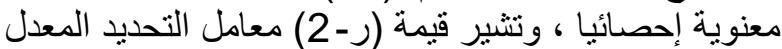
إلى أن نحو 35.3٪ من التغيرات في التكاليف الكلية إنما

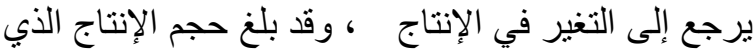

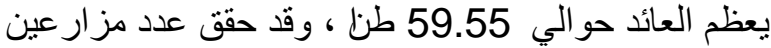

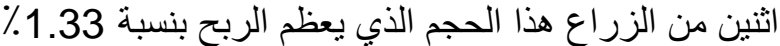

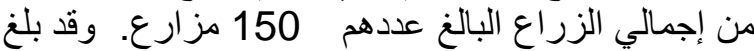

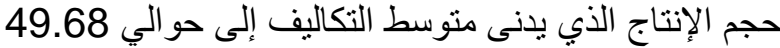

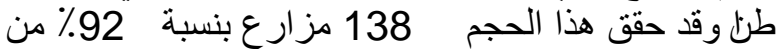

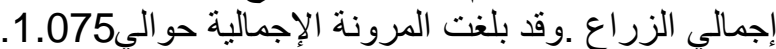

أهم المشكلات الإتتاجية لمحصول قصب السية السكر بمحافظة الإنة

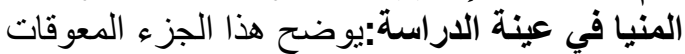

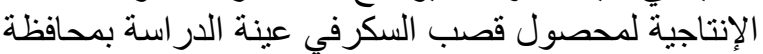

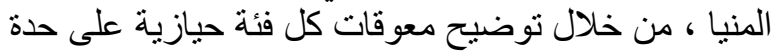
وترتيبها حسب أولويتها وفق الأهمية النسبية لتكر ارها كما كالية
يعظم الربح ، و الحجم الأمثل للإنتاج المدني للتكاليف وذللك

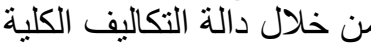
أ - بالنسبة للفئة الحيازية الأولى الكالي

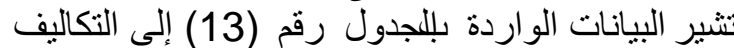

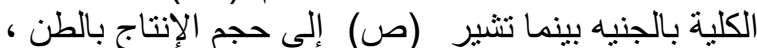

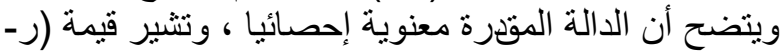

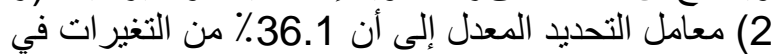
التكاليف الكلية يرجع إلى التغيير في الإنتاج وقد تم التي تقدير التير في

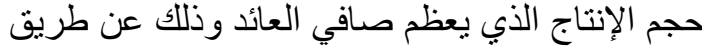

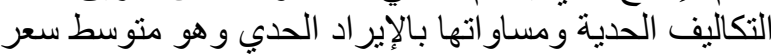

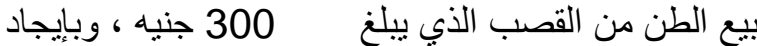
المشتقة الأولى لدالة التكاليف الكلية أمكن الحصول على على الكي

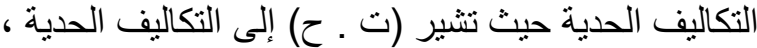

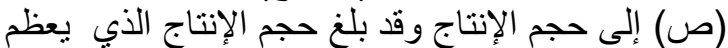

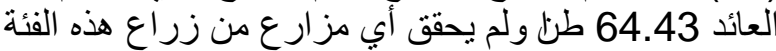

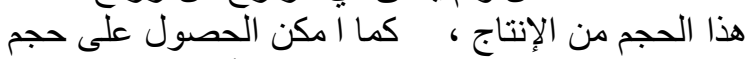

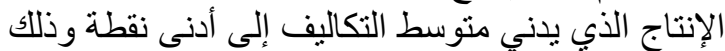

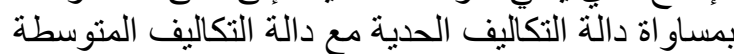
وقد بلغ حجم الإنتاج الذي يدني منوسط التكاليف 51.59

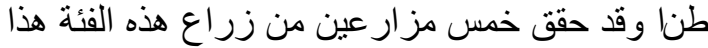

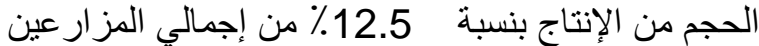

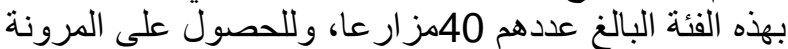
تم قسمة التكاليف الحدية على منوسط التهاليف التهاليف فكانت

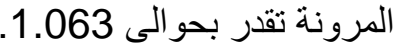
ب ـ بالنسبة للفئة الحيازية الثانية

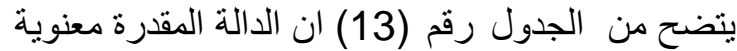

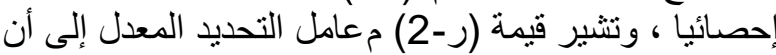

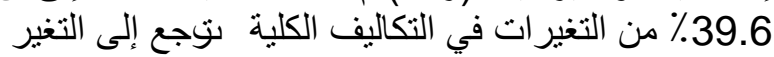

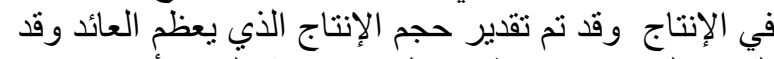

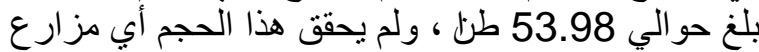

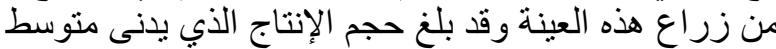

جدول (13) : دوال التكاليف لمحصول قصب السكر للفئات الحيازية بمحافظة المنيا بعينة الدراسة خلال الموسم الزراعي2012/2011.

\begin{tabular}{|c|c|c|c|c|c|c|c|}
\hline \multicolumn{2}{|c|}{ 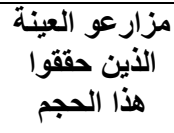 } & \multicolumn{2}{|c|}{ 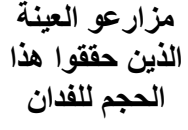 } & \multirow[t]{2}{*}{ قفيمة } & \multirow[t]{2}{*}{ معامل التحديد } & \multirow[t]{2}{*}{ الــــالــــــة } & \multirow[t]{2}{*}{ الفئة الحيازية } \\
\hline$\%$ & عدد & $\%$ & عدد & & & & \\
\hline 12.5 & 5 & - & - & $* * 6.49$ & 0.361 & 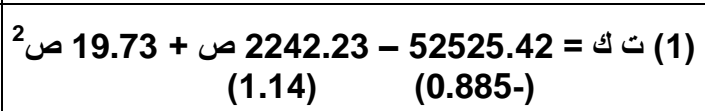 & الفئة الأولى \\
\hline 72.6 & 37 & - & - & *4.45 & 0.396 & 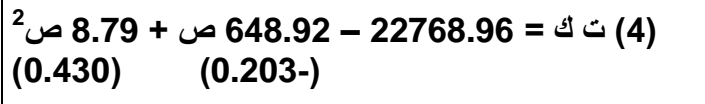 & الفئة الثانية \\
\hline 59.3 & 35 & 3.4 & 2 & **34.55 & 0.536 & 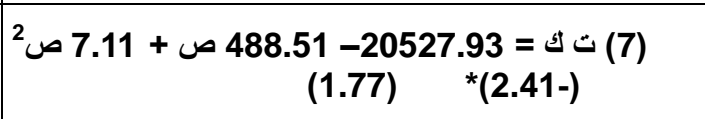 & الفئة الثالثة \\
\hline 92.0 & 138 & 1.33 & 2 & $* * 6.024$ & 0.353 & 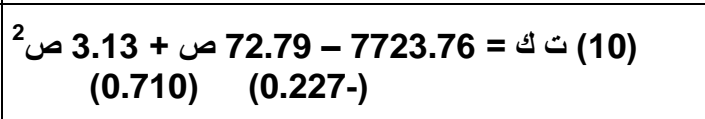 & إجمالى العينة \\
\hline
\end{tabular}

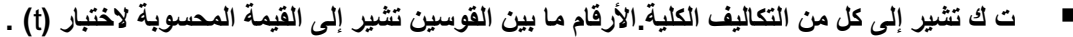


جدول (14) : المشاكل الإتتاجية لمحصول قصب السكر للفئة الحيازية الأولى بعينة الاراسة بمحافظة المنيا

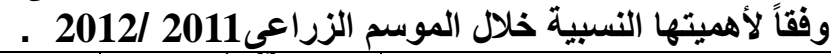

\begin{tabular}{|c|c|c|c|c|}
\hline الترتيب & $\%$ & ن = نَرار 40 & 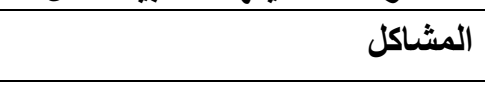 & 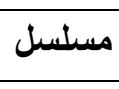 \\
\hline 1 & 100.0 & 40 & ارتفاع أسعار السماد الكيماوي & س1 \\
\hline 1 & 100.0 & 40 & ارتفاع القيمة الإيجارية الفدان & 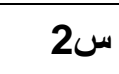 \\
\hline 3 & 72.5 & 29 & ارتفاع أجور العمالة البشرية & س33 \\
\hline- & - & - & انخفاض الإنتاج & 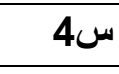 \\
\hline 2 & 75.0 & 30 & عدم توافر العمالة في وقت الحصاد & س55 \\
\hline 6 & 17.5 & 7 & بنتك ألقِرية الحصول على القروض في & 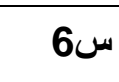 \\
\hline 6 & 17.5 & 7 & صغر حجم الحيازات الزراعية & 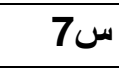 \\
\hline 1 & 100.0 & 40 & ارتفاع أسعار الميكنة الزراعية & 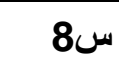 \\
\hline 1 & 100.0 & 40 & انخفاض مناسيب مياه الري & س99 \\
\hline 5 & 20.0 & 8 & انتثار الحشائش بالمحصول & س10 - ا10 \\
\hline- & - & - & انخفاض أسعار بيع المحصول & س11 \\
\hline
\end{tabular}

جدول ( 15) : المشاكل الإنتاجية لمحصول قصب السكر للفئة الحيازية الثانية بعينة الدراسة بمحافظة المنيا وفقاً

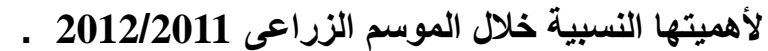

\begin{tabular}{|c|c|c|c|c|}
\hline الترتيب & $\%$ & ن = كراد & المشاكل & مسلسل \\
\hline 1 & 100.0 & 51 & ارتفاع أسعار السماد الكيماوي & 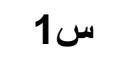 \\
\hline 1 & 100.0 & 51 & ارتفاع القيمة الإيجارية الفدان & 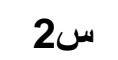 \\
\hline 1 & 100.0 & 51 & ارتفاع أجور العمالة البشرية & س33 \\
\hline 6 & 5.9 & 3 & انخفاض الإنتاج & 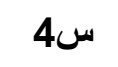 \\
\hline 2 & 96.1 & 49 & عدم توافر العمالة في وقت الحصاد & س \\
\hline 7 & 2.0 & 1 & صعوبة الحصول على القروض في بنك القرية & س66 - س6 \\
\hline- & - & - & صغر حجم الحيازات الزراعية & س77 \\
\hline 1 & 100.0 & 51 & ارتفاع أسعار الميكنة الزراعية & 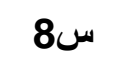 \\
\hline 1 & 100.0 & 51 & انخفاض مناسيب مياه الري & س99 \\
\hline 3 & 92.2 & 47 & انتشار الحشائش بالمحصول & 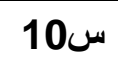 \\
\hline- & - & - & انخفاض أسعار بيع المحصول & 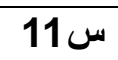 \\
\hline- & - & - & تأخر الإعلان عن أسعار بيع المحصول قبل ميعاد الزراعة & 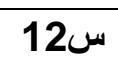 \\
\hline
\end{tabular}




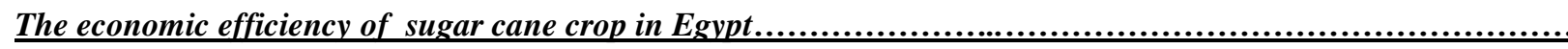

جدول ( 16 ) : المشاكل الإنتاجية لمحصول قصب السكر للفئة الحيازية الثالثة بعينة الدراسة بمحافظة المنيا وفقاً

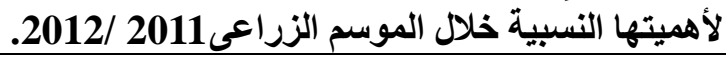

\begin{tabular}{|c|c|c|c|c|}
\hline الترتيب & $\%$ & ن =كرار $5 \stackrel{ }{ }$ & 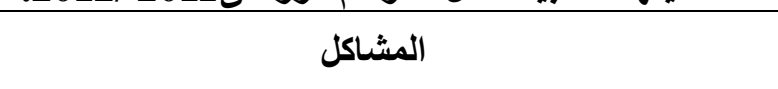 & 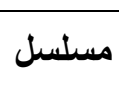 \\
\hline 1 & 100.0 & 59 & ارتفاع اسعار السماد الكيماوي & س11 - س \\
\hline 1 & 100.0 & 59 & ارتفاع القيمة الإيجارية للفدان & 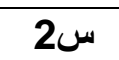 \\
\hline 1 & 100.0 & 59 & ارتفاع أجور العمالة البشرية & س33 \\
\hline 8 & 8.5 & 5 & انخفاض الإنتاج & 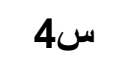 \\
\hline 2 & 98.3 & 58 & عدم توافر العمالة في وقت الحصاد & س55 \\
\hline- & - & - & صعوبة الحصول على القروض في بنك القرية & 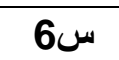 \\
\hline- & - & - & صغر حجم الحياز ات الزراعية & 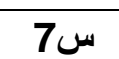 \\
\hline 1 & 100.0 & 59 & ارتفاع أسعار الميكنة الزراعية & س88 \\
\hline 1 & 100.0 & 59 & انخفاض مناسيب مياه الري & س99 \\
\hline 3 & 96.6 & 57 & انتشار الحشائش بالمحصول & س1010 \\
\hline 5 & 23.7 & 14 & انخفاض أسعار بيع المحصول & س \\
\hline 7 & 10.2 & 6 & تأخر الإعلان عن أسعار بيع المحصول قبل ميعاد الزراعة & 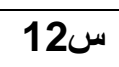 \\
\hline
\end{tabular}

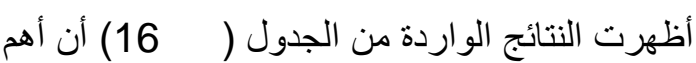

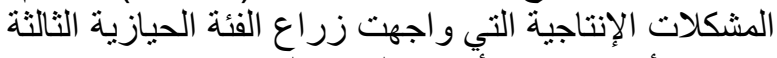

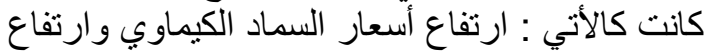

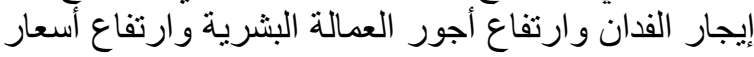

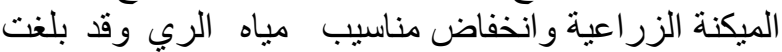

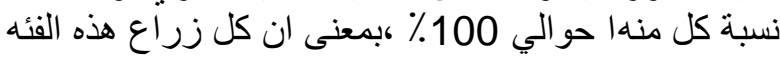

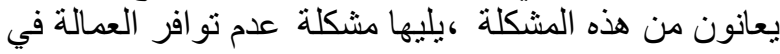

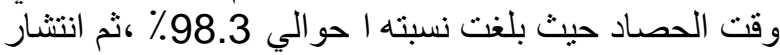

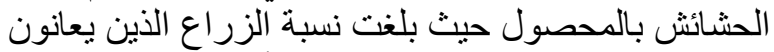

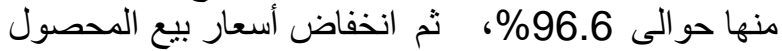

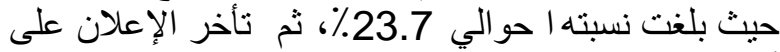

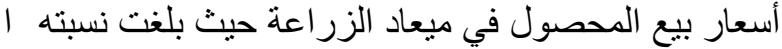

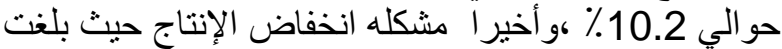

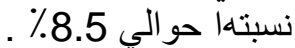
بالنسبة لإجمالي عينة الاراسة

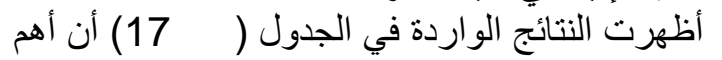

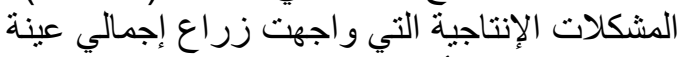

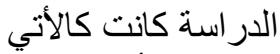
ارتفاع أسعار السماد الكيماوي وارتفاع الزئاع الإيجار للفدان

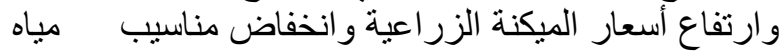

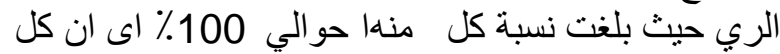

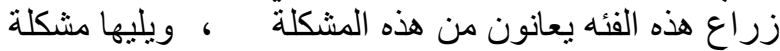

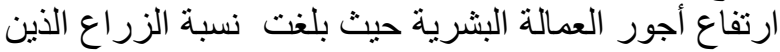

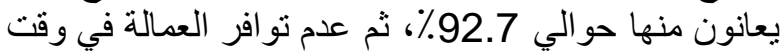

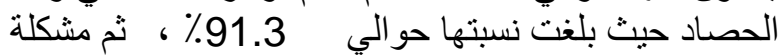
انتشار الحشائش بالمحصول حيث بلغت نسبتها حو الي

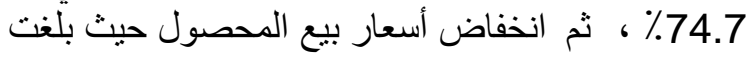

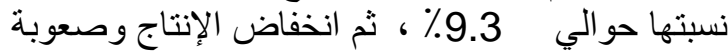
الحصول على القروض من بنلك القرية حيث بلغ الإنغ نسبة كلى
بالنسبة للفئة الحيازية الأولى الفي

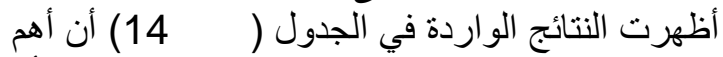

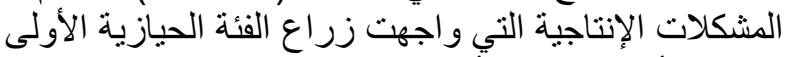

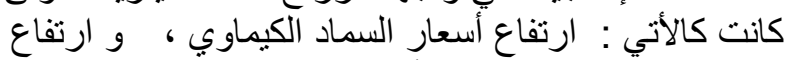

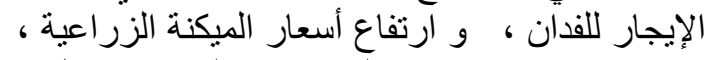

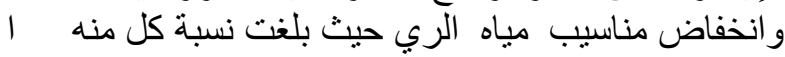

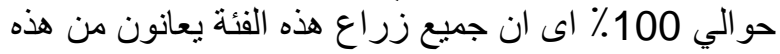

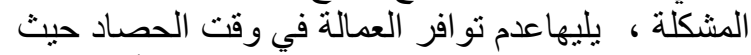

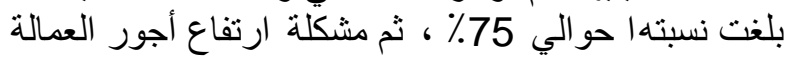

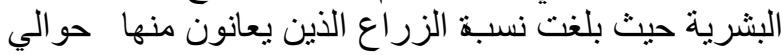

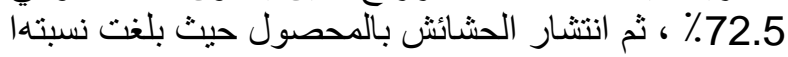

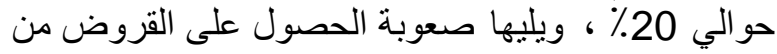

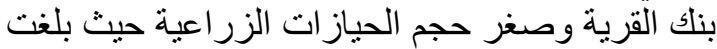

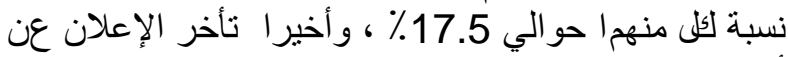

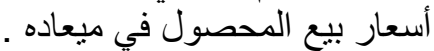

بالنسبة للفئة الحيازية الثانية

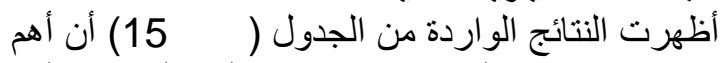

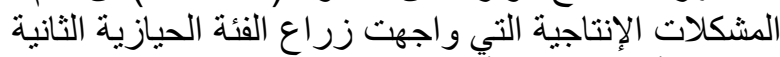

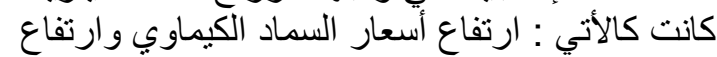

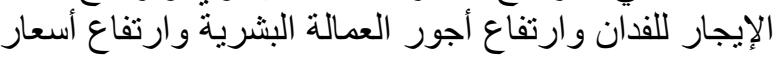

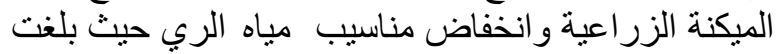

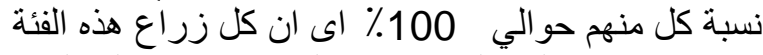

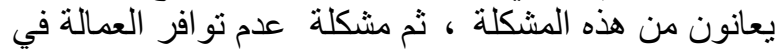

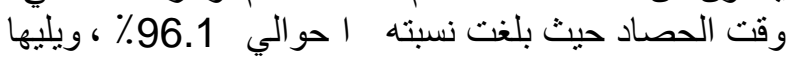

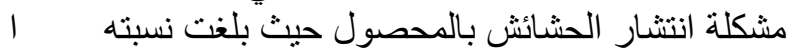

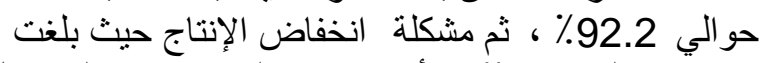

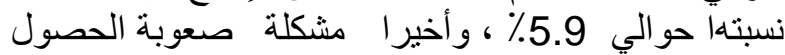
على القروض من بنك القرية حيث بلغت نسبتها حوالي 2. بالنسبة للفئة الحيازية الثالثة 
جدول (17) : المشاكل الإنتاجية لمحصول قصب السكر لإجمالى عينة الدراسة بمحافظة المنيا وفقاً لأهميتها النسبية خلال

\begin{tabular}{|c|c|c|c|c|}
\hline \multicolumn{5}{|c|}{ الموسم الزراعى 2012/2011 م. } \\
\hline الترتيب & $\%$ & $\begin{array}{l}\text { تكرار } \\
=0 \\
150\end{array}$ & المشاكل & مسلسل \\
\hline 1 & 100.0 & 150 & ارتفاع أسعار السماد الكيماوي & س1 - س \\
\hline 1 & 100.0 & 150 & ارتفاع القيمة الإيجارية للفدان & س2 \\
\hline 2 & 92.7 & 139 & ارتفاع أجور العمالة البشرية & س33 \\
\hline 8 & 5.3 & 8 & انخفاض الإنتاج & 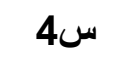 \\
\hline 3 & 91.3 & 137 & عدم توافر العمالة في وقت الحصاد & س55 \\
\hline 8 & 5.3 & 8 & صعوبة الحصول على القروض في بنك القرية & 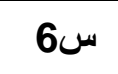 \\
\hline 9 & 4.7 & 7 & صغر حجم الحيازات الزراعية & س77 \\
\hline 1 & 100.0 & 150 & ارتفاع أسعار الميكنة الزراعية & س88 \\
\hline 1 & 100.0 & 150 & انخفاض مناسيب مياه الري & س99 \\
\hline 4 & 74.7 & 112 & انتشار الحشائش بالمحصول & س10 \\
\hline 7 & 9.3 & 14 & انخفاض أسعار بيع المحصول & 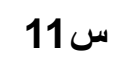 \\
\hline 9 & 4.7 & 7 & تأخر الإعلان على أسعار بيع المحصول قبل ميعاد الزراعة & س12 - اس \\
\hline
\end{tabular}

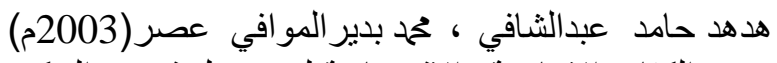

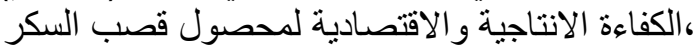

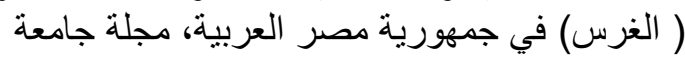

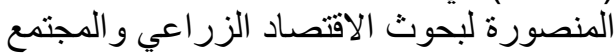

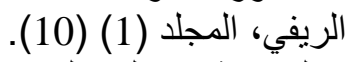

وزارة الزراعة ، مجلس المحاصيل السكرية، انتاج السكر الإلئ في مصر وموقف الاستهلاك المحلي و الاكتفاء الذاتي التئي

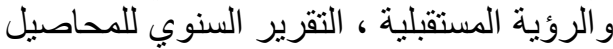
السكرية ، القاهرة ، اعداد مختلفة.

وزارة الزر اعة و استصلاح الار اضي ،قاعة الزاع الثئون الاقتصادية نشرة الاقتصاد الزر اعي، اعداد الزاد مختلفة.

Mohmoud Mansour "Implication Of Economic Reform On Supporting Services To Agriculture In The New Lands" FAO, Cairo Office, 1998

Report of Peter Gleick . The Word's Water 2002 2003 : The Bienniol Report Of Fresh Water Resources , Washington D.C. , Island Pres , 2002.P.19.

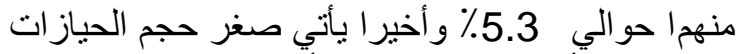

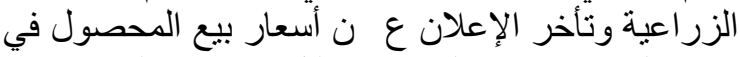

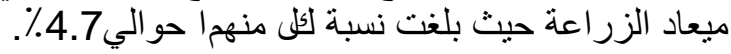

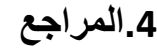

آدم ، حسين حسن علي (2004م)|قتصاديات انتاج المحاصيل

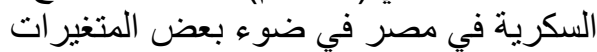

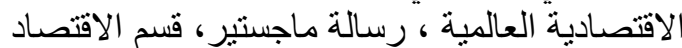
الزراعي، كلية الزراعة، جامعة عين شمس.

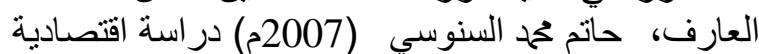

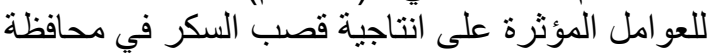

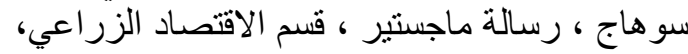

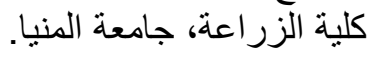

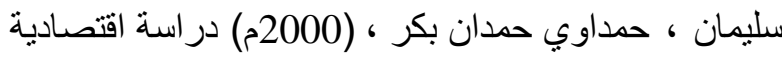

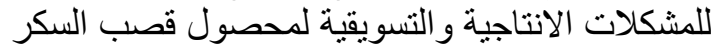

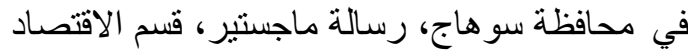

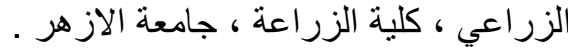
مديرية الزر آعة بإلمنيا، قسم الإحصاءة، جياناتات غير منشورة. 